\title{
Light-Driven Reduction of Aromatic Olefins in Aqueous Media Catalysed by Aminopyridine Cobalt Complexes.
}

\author{
Carla Casadevall, ${ }^{1}$ David Pascual, ${ }^{1}$ Jordi Aragón, ${ }^{1}$ Arnau Call, ${ }^{1}$ Alicia Casitas, ${ }^{1}$ Irene Casademont,${ }^{2}$ and \\ Julio Lloret-Fillol ${ }^{1,3^{*}}$ \\ ${ }^{1}$ Institute of Chemical Research of Catalonia (ICIQ), The Barcelona Institute of Science and Technology, Avinguda Països \\ Catalans 16, 43007 Tarragona, Spain. \\ ${ }^{2}$ Donostia International Physics Center (DIPC)Donostia,Euskadi (Spain). \\ ${ }^{3}$ Catalan Institution for Research and Advanced Studies (ICREA), Passeig Lluïs Companys, 23, 08010, Barcelona (Spain).
}

\begin{abstract}
A catalytic system based on earth-abundant elements that efficiently hydrogenates aryl olefins using visible light as driving-force and $\mathrm{H}_{2} \mathrm{O}$ as the sole hydrogen atoms source is reported. The catalytic system involves a robust and well-defined aminopyridine cobalt complex and a heteroleptic $\mathrm{Cu}$ photoredox catalyst. The system shows the reduction of styrene in aqueous media with a remarkable selectivity (> 20000) versus water reduction (WR). Reactivity and mechanistic studies support the formation of a $[\mathrm{Co}-\mathrm{H}]$ intermediate, which reacts as a hydrogen transfer agent (HAT). Synthetically useful deuterium-labelled compounds can be straightforwardly obtained by replacing $\mathrm{H}_{2} \mathrm{O}$ with $\mathrm{D}_{2} \mathrm{O}$ and using only catalysts based on earth-abundant elements. Moreover, the dual photocatalytic system and the photocatalytic conditions can be rationally designed to tune the selectivity for aryl olefin vs aryl ketone reduction; not only by changing the structural and electronic properties of the cobalt catalysts, but also by modifying the reduction properties of the light-harvesting system.
\end{abstract}

KEYWORDS: Reduction chemistry, artificial photosynthesis, photocatalysis, solar fine chemicals, cobalt complexes.

\section{INTRODUCTION}

The use of sunlight as driving force is a promising but challenging strategy towards sustainability in chemical production. ${ }^{1}$ Artificial photosynthesis (AP), as a technology to provide a clean source of reductive equivalents, ${ }^{1 \mathrm{~d}, 2}$ has been mainly studied in the context of $\mathrm{H}_{2} \mathrm{O}^{3}$ and $\mathrm{CO}_{2}{ }^{4}$ reduction, with

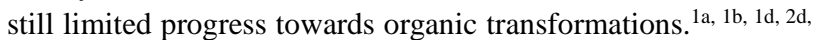
5 A challenging transformation in the context of AP is the hydrogenation of double bonds. ${ }^{2 \mathrm{~d}}$ Amount difficulties, most developed protocols employing the activation of $\mathrm{H}_{2}$, silanes or alcohols are not suitable to operate in aqueous conditions. ${ }^{6}$ And, only few studies used light as a driving force and most of them have been carried out in the absence of water as a solvent. Moreover, selectivity of olefin reduction versus water reduction is needed for achieving a practical use in the context of AP. In the case of aromatic olefins, they are prompted to form radicals, tending to polymerize under such conditions. ${ }^{7}$

Initial reports in the context of AP used semiconductor materials such as $\mathrm{TiO}_{2}$ and $\mathrm{CdS}$ for the light-driven hydrogenation of electron-deficient olefins. In this case, UV light $(\lambda=365 \mathrm{~nm})$ and noble metals were needed to obtain low/moderate selectivity for alkene production (Scheme 1). ${ }^{8}$ Another remarkable example employed a $\mathrm{B}_{12}-\mathrm{TiO}_{2}$ hybrid for the UV light-driven reduction of alkenes to alkanes. ${ }^{9}$ Such highly energetic conditions led to formation of dimeric products harming the selectivity. ${ }^{10}$

Holland, Corma and coworkers introduced the stereoselective hydrogenation of the conjugated $\mathrm{C}=\mathrm{C}$ bond of ketoisophorone by combining the photocatalytic activity of $\mathrm{Au}$ nanoparticles supported on $\mathrm{TiO}_{2}$ with the enzymatic activity of oxidoreductases by means of $\mathrm{FAD}^{+}$as mediator and cofactor (Scheme 1). ${ }^{5 \mathrm{~d}}$

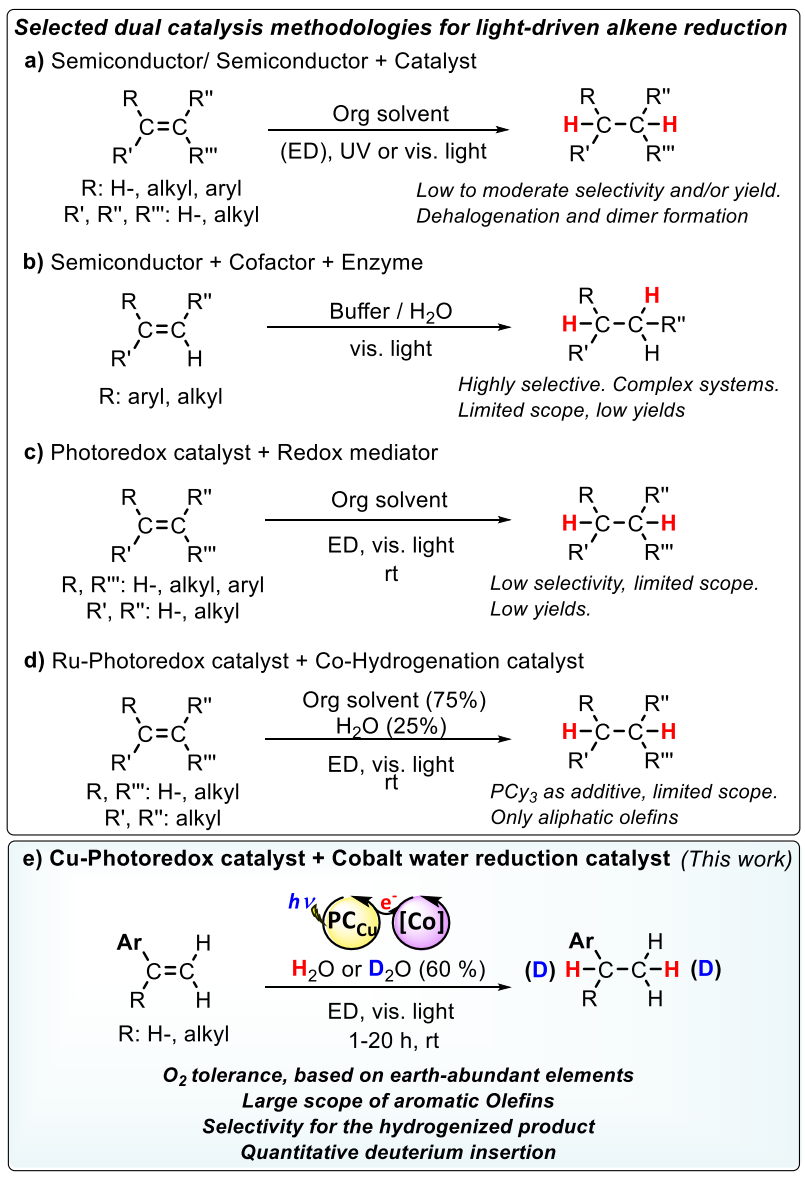

Scheme 1. Selected dual catalysis methodologies for the light driven reduction of olefins. Abbreviations: ED: electron donor. Selected references: (a) refs. 8, 10, (b) refs. 5d and 11, (c) ref. 12, (d) ref. 13 and (e) developed methodology in this study.

Likewise, Hartwig, Zhao and coworkers reported a cooperative chemoenzymatic reaction that combines the isomerization of $\mathrm{C}=\mathrm{C}$ by an iridium photoredox catalyst with the hydrogenation 
activity of ene-reductases to selectively reduce electron-deficient aromatic olefins to their corresponding alkanes in high enantiomeric excess (88-99\% ee) ${ }^{11}$ All of these works show that light-driven reduction of olefins is a feasible transformation, albeit limited in substrate scope, selectivity and yield.'

Very recently, X. C. Cambeiro and co-workers reported the use of and iridium photosensitizer in combination with a Hantzsch ester for the reduction of aromatic 1,2-disubstituted olefins, albeit moderate to high yields were obtained only for limited substrate scope. ${ }^{12}$ At the same time, M Kojima, S. Matsunaga and co-workers found that glyoxime type complexes with the $\mathrm{PCy}_{3}$ ligands and a ruthenium photoredox catalyst reduced aliphatic olefins via a hydrogen atom transfer (HAT) mechanism. ${ }^{13}$ It is known that cobalt hydride complexes can undergo HAT to alkenes. $^{6 c}$ However, aromatic olefines have additional difficulties such as their tendency to polymerize forming radicals $^{7}$ or isomerize ${ }^{14}$ under reductive conditions, which makes them harder to reduce under photocatalytic conditions, and were not reported in their study (Scheme 1). By a conceptually different approach, X. Guo, O. S. Wenger and co-workers recently reported the reduction of olefins by the photo-HAT reactivity of the organometallic iridium hydride complex $\left[\mathrm{Cp} * \mathrm{Ir}^{\mathrm{II}}\right.$ (phen)-H] in degassed acetonitrile. ${ }^{15}$ And Polyzos and co-workers showed the reduction of aromatic olefins via direct photoinduced electron transfer, at expense of highly reductive conditions and light intensity. ${ }^{16}$

A suitable approach for AP should employ water as source of hydrogen atoms and efficiently use the photoredox catalyst in combination with molecular catalysts to facilitate the selective reduction of alkanes. Such approach should locate hints of catalysts to be coupled with more complex AP schemes. With this idea in mind, we previously found that a dual catalytic system formed by $\left[\mathrm{Co}(\mathrm{OTf})\left(\mathrm{Py}_{2}{ }^{\mathrm{Ts}}\right.\right.$ tacn $\left.)\right](\mathrm{OTf})(\mathbf{1})\left(\mathrm{Py}_{2}{ }^{\mathrm{Ts}}\right.$ tacn $=$ 1,4-di(picolyl)-7-(p-toluenesulfonyl)-1,4,7-triazacyclononane, OTf $=$ trifluoromethanesulfonate anion) as a reduction catalyst, and $[\mathrm{Cu}$ (bathocuproine)(xantphos) $]\left(\mathrm{PF}_{6}\right)^{17} \quad\left(\mathbf{P C}_{\mathbf{C u}}\right)$ as a photoredox catalyst was able to efficiently reduce water to hydrogen ${ }^{18}$ and carbonyl groups to alcohols using water as a hydrogen source. ${ }^{5 \mathrm{k}}$ Our mechanistic studies suggested that a cobalt(II) hydride $\left(\left[\mathrm{Co}(\mathrm{H})\left(\mathrm{Py}_{2}{ }^{\mathrm{Ts}} \operatorname{tacn}\right)\right]^{+},\left[\mathrm{Co}^{\mathrm{II}}-\mathrm{H}\right]\right)$ was a common intermediate in both reduction reactions. Based on these precedents, we hypothesized that $\left[\mathrm{Co}(\mathrm{H})\left(\mathrm{Py}_{2}{ }^{\mathrm{Ts}} \mathrm{tacn}\right)\right]^{+}$should also be reactive enough to engage in the reduction of other organic functionalities without the need for strong reducing agents. ${ }^{5 \mathrm{~m}}$
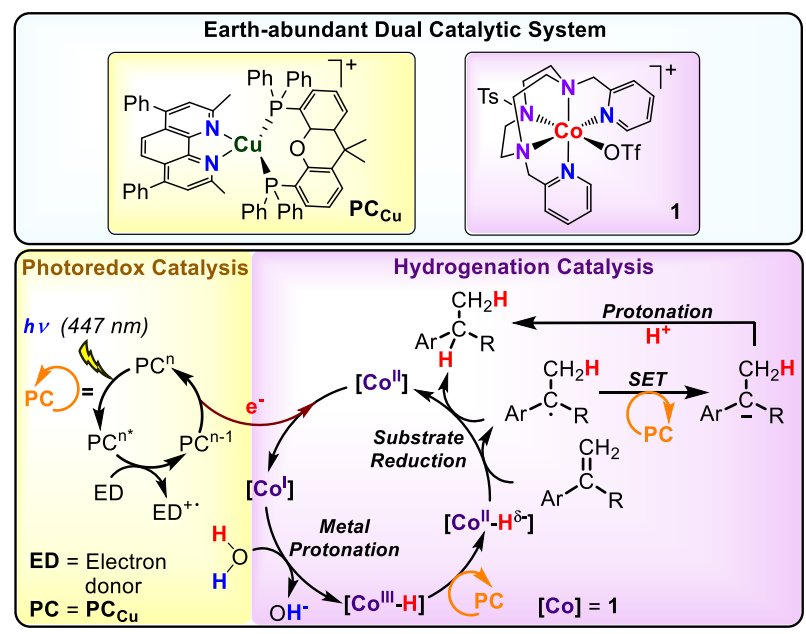

Scheme 2. Earth-abundant dual catalytic system for the photoreduction of aromatic olefins.
Herein, we present the catalytic performance of a dual catalytic system consisting of cobalt complexes based on nitrogenated ligands (1-15) as a reduction catalyst, together with different Ir and $\mathrm{Cu}$ photoredox catalysts and an electron donor for the reduction of styrene derivatives using light as an energy source. The reduction operates without the use of typical reducing agents such as silanes, $\mathrm{H}_{2}, \mathrm{HCO}_{2} \mathrm{H}$ or alcohols. The best performing catalytic system consist in $\left[\mathrm{Co}(\mathrm{OTf})\left(\mathrm{Py}_{2}{ }^{\mathrm{Ts}} \operatorname{tacn}\right)\right](\mathrm{OTf})(\mathbf{1})$ and $\mathbf{P C}_{\mathbf{C u}}$ under light irradiation employing $\mathrm{H}_{2} \mathrm{O} / \mathrm{Et}_{3} \mathrm{~N}$ as a hydride source (Scheme 2). ${ }^{5 \mathrm{k}-\mathrm{n}}$ This synthetic methodology also allows for replacing $\mathrm{H}_{2} \mathrm{O}$ by $\mathrm{D}_{2} \mathrm{O}$ to produce the deuterated alkanes. Reactivity and mechanistic studies based on kinetics, isotopic labelling and experiments with radical clocks suggested that the reduction of aromatic olefins occurs via a HAT mechanism, most likely through a $[\mathrm{Co}-\mathrm{H}]$. According to our mechanistic findings, the interplay between the catalyst / substate redox potential, together with the light intensity, provide a way to control the selectivity for the reduction of aromatic olefins versus aromatic ketones and vice versa. This unique behavior is rationalized by the different reduction mechanism that undergoes each substrate.

\section{RESULTS AND DISCUSSION}

Based on previous studies, ${ }^{5 \mathrm{k}, 51}$ we hypothesized that the putative $\left[\mathrm{Co}(\mathrm{H})\left(\mathrm{Py}_{2}{ }^{\mathrm{Ts}} \text { tacn }\right)\right]^{+}$intermediate formed under photochemical conditions may engage in the reduction of more challenging substrates. First, we explored styrene (16) as model substrate and found that it was reduced in good yield. The irradiation $(\lambda=447$ $\left.\pm 20 \mathrm{~nm}, \mathrm{~T}=35^{\circ} \mathrm{C}\right)$ of a solution containing styrene $(\mathbf{1 6}, 16.5$ $\mathrm{mM})$, complex 1 (1 mol\%) as reduction catalyst, $\mathbf{P C}_{\mathbf{C u}}(1.5$ mol\%) as photoredox catalyst, and $\mathrm{Et}_{3} \mathrm{~N}(0.2 \mathrm{~mL}, 8.5$ equiv. $)$ as a sacrificial electron donor in a $\mathrm{H}_{2} \mathrm{O}: \mathrm{CH}_{3} \mathrm{CN}(6: 4 \mathrm{~mL})$ solvent mixture, produces ethylbenzene (16a) as the major product (67 $\%$ yield) (Table S.4 entry 1). The reduction of styrene was accompanied with the formation of the dimerization product of styrene (butane-2,3-diyldibenzene, $\mathbf{1 6 b}, 11 \%$ yield). The detection of the homocoupling product suggests the formation of benzylic radicals during the reaction, whose mechanistic implications will be discussed later in the mechanistic section.

Screening of conditions and catalytic system: The formation of the homocoupling product $\mathbf{1 6} \mathbf{b}$ was significantly minimized (4 $\%$ ) by increasing the catalyst and photoredox catalyst loadings (from 1.5 to $3 \mathrm{~mol} \%$ ) and reducing the styrene concentration (from 16.5 to $8.7 \mathrm{mM}$ ), yielding ethylbenzene (16a) in $86 \%$. Further refinement of the reaction conditions was achieved by adjusting the reaction temperature. It is worth to notice that the reaction yield and selectivity are sensitive to the temperature. At $35^{\circ} \mathrm{C}$ or higher, the yield of the reduced product drops in favor of the formation of the reductive homocoupling product. Therefore, the reaction temperature should be effectively controlled to prevent warming by light irradiation. About $45^{\circ} \mathrm{C}$ were measured in non-thermostated reactions.

We have used an in-house developed parallel photoreactor to precisely control the temperature and light intensity (see SI for further details)..$^{5 \mathrm{k}, 19}$ At $25^{\circ} \mathrm{C}$ the formation of the homocoupling product was only $3 \%$ (Table 1 , entry 4 ) and negligible at $15{ }^{\circ} \mathrm{C}$ (Table 1, entry 5, Table S4). At lower temperatures, the homocoupling product was avoided. We rationalized that the reduction of the selectivity at higher temperature is most likely due to accumulation of benzylic radicals, which dimerize when are present in higher quantities. Under optimized conditions, the hydrogenation of styrene yields 16a in $91 \%$ without detection of dimeric products (Table 1 entry 5). 
Table 1. Optimization of the catalytic conditions for the reduction of $\mathbf{1 6}$ using $\mathbf{P C}_{\mathbf{C u}}$ as photoredox catalyst and $\mathbf{1}$ as catalyst.
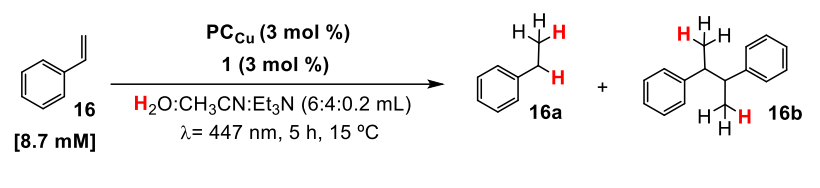

\begin{tabular}{lccc}
\hline \multirow{2}{*}{ Entry } & Deviation from conditions & $\%$ & $\%$ \\
& $16 a$ & $16 b$
\end{tabular}

\begin{tabular}{|c|c|c|c|}
\hline 1 & $\begin{array}{c}16.5 \mathrm{mM} \mathrm{16}, 35^{\circ} \mathrm{C} \\
\mathbf{1}(1 \mathrm{~mol} \%), \mathbf{P C C u}(1.5 \mathrm{~mol} \%)\end{array}$ & 67 & 11 \\
\hline 2 & $16.5 \mathrm{mM} \mathrm{16}, 35^{\circ} \mathrm{C}$ & 81 & 6 \\
\hline 3 & $35^{\circ} \mathrm{C}$ & 86 & 4 \\
\hline 4 & $25^{\circ} \mathrm{C}$ & 90 & 3 \\
\hline 5 & None & 91 & n.d. \\
\hline 6 & No light & n.d. & n.d. \\
\hline 7 & $\mathrm{No} \mathrm{Et}_{3} \mathrm{~N}$ & n.d. & n.d. \\
\hline 8 & No $\mathrm{PC}_{\mathrm{Cu}}$ & n.d. & n.d. \\
\hline 9 & No 1 & n.d. & n.d. \\
\hline 10 & $\mathrm{Co}(\mathrm{OTf})_{2}(\mathrm{MeCN})_{2}$ instead of $\mathbf{1}$ & n.d. & n.d. \\
\hline 11 & $\begin{array}{c}{\left[\mathrm{Co}(\mathrm{OTf})_{2}(\mathrm{MeCN})_{2}+\mathrm{Py}_{2}{ }^{\mathrm{Ts}} \operatorname{tacn}\right] \text { instead of }} \\
\mathbf{1}\end{array}$ & 91 & n.d. \\
\hline 12 & ${ }^{{ }^{P}} \mathbf{P C} \mathbf{c u}$ instead of $\mathbf{P C}_{\mathbf{C u}}$ & 21 & n.d. \\
\hline 13 & ${ }^{\text {So3 }} \mathbf{P C}_{\mathrm{Cu}}$ instead of $\mathbf{P C}_{\mathbf{C u}}$ & 78 & n.d. \\
\hline 14 & ${ }^{\mathbf{H}} \mathbf{P C}_{\mathbf{I r}}$ instead of $\mathbf{P C} \mathbf{C u}$ & 11 & 8 \\
\hline 15 & ${ }^{\text {NMe2 }} \mathbf{P} C_{\text {Ir }}$ instead of $\mathbf{P C} \mathbf{C u}$ & 67 & n.d. \\
\hline 16 & ${ }^{{ }^{C O 2 H}} \mathbf{P C}$ Ir instead of $\mathbf{P C} \mathbf{C u}$ & 47 & 8 \\
\hline 17 & $\mathbf{1}_{\mathrm{Ni}}$ instead of $\mathbf{1}$ & n.d. & n.d. \\
\hline
\end{tabular}

Conditions: 1 (\% $\mathrm{mol}), \mathbf{P C}(\% \mathrm{~mol}), \mathbf{1 6}(\mathrm{mM})$ as indicated in the table in $\mathrm{H}_{2} \mathrm{O}: \mathrm{CH}_{3} \mathrm{CN}: \mathrm{Et}_{3} \mathrm{~N}(6: 4: 0.2 \mathrm{~mL})$ irradiation at $\lambda=447 \mathrm{~nm}$ for $5 \mathrm{~h}$ at 35 , 25 or $15^{\circ} \mathrm{C}$ under $\mathrm{N}_{2}$. Yields were determined by GC analysis after workup of the reaction and relative to a calibrated internal standard. Values are average of triplicates. $\left[\mathrm{Ni}(\mathrm{OTf})\left(\mathrm{Py}_{2}{ }^{\mathrm{Ts}} \mathrm{tacn}\right)\right](\mathrm{OTf})\left(\mathbf{1}_{\mathrm{Ni}}\right)$. See SI for the synthesis and characterization of metal complexes.

Control experiments determined that all components of the photocatalytic system (light, cobalt catalyst, photoredox catalyst and electron donor) are necessary for the formation of 16a or 16b. In the absence of light, $\mathbf{1}, \mathbf{P C}_{\mathbf{C u}}$, or $\mathrm{Et}_{3} \mathrm{~N}$ (Table 1 entries 69) no 16a nor 16b were observed. To discard the benzylic radials formation from a direct reduction by single electron transfer (SET) from the reduced photoredox catalyst ([Cu(bathocuproine)(xantphos) $\left.], \quad\left[\mathbf{P C}_{\mathbf{C u}}\right]^{\mathbf{0}}\right)$, we performed photocatalytic studies in absence of complex 1 . Even when the reaction was performed at $55^{\circ} \mathrm{C}$ using $32 \mathrm{mM}$ of 16 and $10 \mathrm{~mol} \%$ PCCu, no dimeric products were observed, discarding direct SET from the photoredox catalyst to form the benzylic radicals (Table S.5). Indeed, the reduced photoredox catalyst is not reductive enough to transfer an electron to $\mathbf{1 6}\left(\mathrm{E}\left(\mathrm{PC}_{\mathrm{Cu}}^{\mathrm{u}}\right)=-1.60\right.$ and $\mathrm{E}_{\text {red }}$ $=-2.31 \mathrm{~V} v s \mathrm{SCE}$ for 16). Additionally, no reduced products were detected when 1 was replaced by cobalt salts such as the starting cobalt(II) triflate $\left(\mathrm{Co}(\mathrm{OTf})_{2}(\mathrm{MeCN})_{2}\right.$, Table 1 entry 10$)$. We found practical that $\mathbf{1 6}$ could be fully converted when complex $\mathbf{1}$ was formed in situ under catalytic conditions by adding the
$\mathrm{Py}_{2}{ }^{\mathrm{Ts}}$ tacn ligand with an equimolar amount of $\mathrm{Co}(\mathrm{OTf})_{2}(\mathrm{MeCN})_{2}$ (Table 1 entry 11 ).

The effect of the photoredox catalyst: On the other hand, replacement of the photoredox catalyst $\mathbf{P C}_{\mathbf{C u}}$ by $[\mathrm{Cu}$ (bathocuproine-I)(Xantphos) $]\left(\mathrm{PF}_{6}\right) \quad\left(\mathbf{I P C}_{\mathbf{C u}}\right)$ or $\left[\mathrm{Cu}\left(\right.\right.$ bathocuproine- $\left.\mathrm{SO}_{3}{ }^{-}\right)($xantphos $\left.)\right](\mathrm{Na}) \quad\left({ }^{{ }^{S O} 3} \mathbf{P C}_{\mathrm{Cu}}\right)$ produced 16a in lower yield (21 and $78 \%$, respectively). We also tested three different iridium photosensitizers with different substituents on the bipyridine that tuned their redox potential: $\left[\operatorname{Ir}(\mathrm{ppy})_{2}(\mathrm{bpy})\right]\left(\mathrm{PF}_{6}\right)\left({ }^{\mathrm{H}} \mathbf{P C} \mathrm{Ir}\right),\left[\operatorname{Ir}(\mathrm{ppy})_{2}(\mathrm{dcbpy})\right]\left(\mathrm{PF}_{6}\right)\left({ }^{\mathrm{CO}_{2}} \mathrm{H}_{\mathbf{P C}} \mathrm{Ir}_{\mathbf{r}}\right)$ and $\left[\operatorname{Ir}(\mathrm{ppy})_{2}(\mathrm{dmab})\right]\left(\mathrm{PF}_{6}\right)\left({ }^{\mathrm{NMe} 2} \mathbf{P C}\right.$ Ir $)$ (Table 1 entries $12-16$ and Figure S.21). Obtained yields showed only a weak correlation with the PC redox potentials despite higher product yields are obtained with the more reducing photoredox catalysts $\left({ }^{\mathrm{CO}_{2}} \mathrm{H}_{\mathbf{P C}} \mathrm{C}_{\mathbf{I r}}\right.$, ${ }^{\mathrm{H}} \mathbf{P C}_{\mathrm{Ir}},{ }^{\mathrm{I}} \mathbf{P C}_{\mathbf{C u}}, \mathbf{P C}_{\mathbf{C u}},{ }^{\mathrm{SO} 3} \mathbf{P C}_{\mathbf{C u}},{ }^{\mathrm{NMe}} \mathbf{P C}_{\mathrm{Ir}}, \mathrm{E}^{\mathrm{I} / 0}=-1.10,-1.40,-$ 1.47, -1.60, -1.66, -1.80 V vs SCE yielded 47, 11, 21, 91, 78, 67 $\%$ of 16a, respectively), suggesting an interplay between the photochemical properties of photocatalysts, cobalt catalysts and substrates. For instance, for the most reducing PC there is a change in selectivity, the amount of $\mathbf{1 6} \mathbf{b}$ was higher which could be interpreted as a faster formation of benzylic radicals and therefore higher dimerization and formation of other byproducts. On the other hand, in the absence of catalyst we observed negligible styrene reduction.

The effect of the cobalt complex: Then, we explored the capacity of other cobalt complexes as catalysts including tetra- and pentadentate aminopyridine cobalt complexes found active for photochemical ketone reduction, ${ }^{5 \mathrm{k}}$ as well as commercially available cobaloxime and vitamin $B_{12}$ to reduce $\mathbf{1 6}$ under the stablished standard photocatalytic conditions (Table 2). Interestingly, the photocatalytic activity varies depending on the nature of the complex.

But a correlation between a molecular property of the complex and the reaction yield is not evident. For instance, the lowest yield was obtained by complex $\mathbf{7}$, which has also the lowest reduction potential of table 2 , whereas the highest yield was obtained by complex $1\left(\mathrm{E}^{\mathrm{I} / \mathrm{I}}=-0.97\right.$ and $-1.15 \mathrm{~V}$ vs SCE, respectively, Figure S.20). Nevertheless, we noticed that complexes with the tacn moiety at the ligand are among the best catalysts. On the other hand, replacing the cobalt center by nickel in complexes 1, 2 and $\mathbf{6}$ did not yield any reduced product.

Selectivity $16 \boldsymbol{a}$ versus $16 \boldsymbol{b}$ : Selectivity towards olefin reduction versus homocoupling product (Sel 16a/16b calculated as $\mathrm{n}(\mathbf{1 6 a}) / \mathrm{n}(\mathbf{1 6} \mathbf{b}))$ varies depending on the cobalt complex. Among the series tested, complex 1 was the most efficient and selective catalyst for olefin reduction ( $91 \%$ yield $\mathbf{1 6 a},<1 \%$ yield $\mathbf{1 6 b}$, Sel16a/16b = 91). The results evidenced that the tacn ligand scaffold (1 and $\mathbf{9}-\mathbf{1 4})$ provides the best yield and an excellent selectivity for the reduction of $\mathbf{1 6}$ (yield 76 to $91 \%$, Sel $16 \mathrm{a} / \mathbf{1 6 b}=$ 91-11, Table 2 and Figure S.23). Catalysts 2-7 (aminopolypyridyl ligands) yielded a maximum of $47 \%$ for $\mathbf{1 6 a}$, accompanied with a loss in selectivity $\left(\operatorname{Sel}_{16 a / 16 b}=24-2.6 \%\right)$. Cobaloxime $\left(\left[\mathrm{Co}{ }^{\mathrm{III}}(\mathrm{Cl})(\mathrm{Py})(\right.\right.$ Glioxim $\left.\left.)\right], 8\right)$ achieved 16a in $51 \%$ but with significant higher amount of $\mathbf{1 6 b}$ as by-product $(25 \%$ yield, Sel $\left.\mathbf{1 6}_{\mathbf{6}} / \mathbf{1 6} \mathbf{b}=2\right)$. Whereas vitamin $B_{12}$ was the less active and selective catalyst of the series, yielding only traces of both reduced and dimeric products (4 and $6 \%$ yield, respectively, Sel $\left._{16 a / 16 b}=0.7 \%\right)$. 


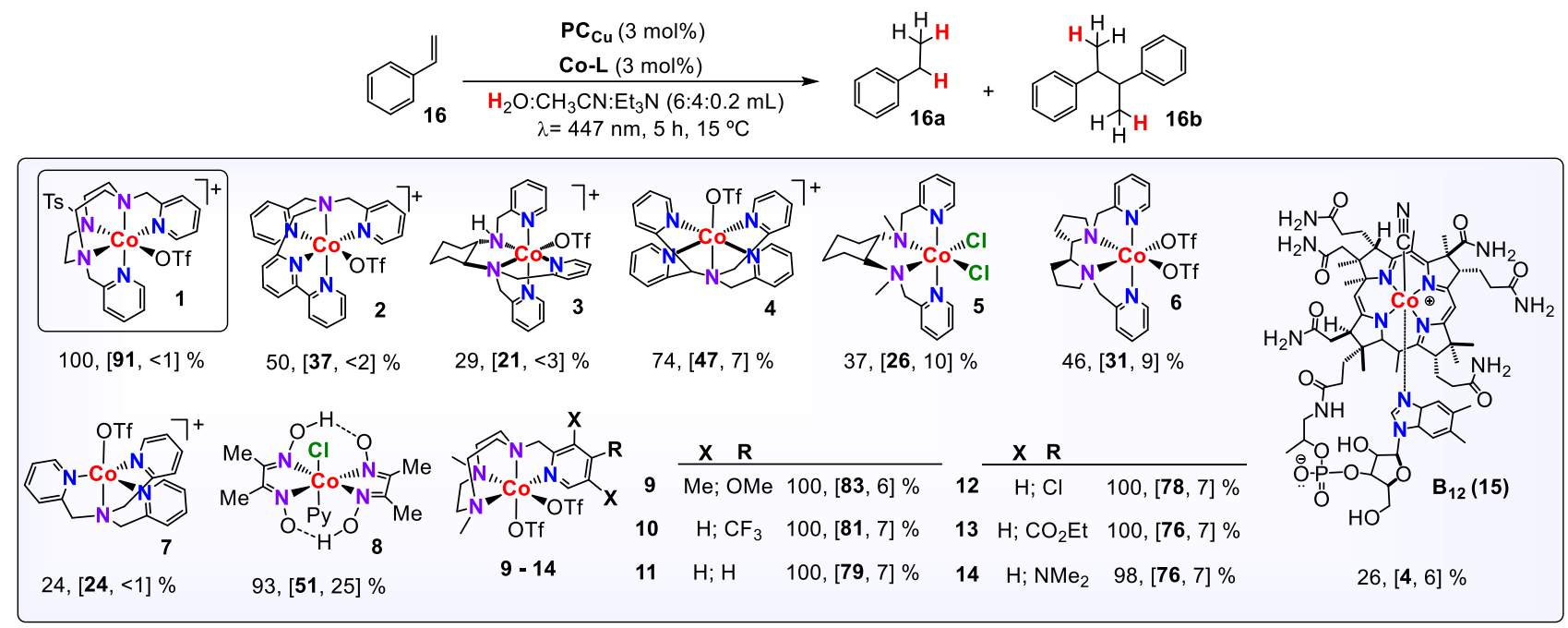

Selected WR complexes: 1: $\left[\mathrm{Co}^{\mathrm{II}}(\mathrm{OTf})\left(\mathrm{Py}_{2}{ }^{\mathrm{Ts}} \mathrm{tacn}\right)\right](\mathrm{OTf}), \mathbf{2}:\left[\mathrm{Co}^{\mathrm{II}}(\mathrm{OTf})(\mathrm{DPA}-\mathrm{Bpy})\right](\mathrm{OTf}), \mathbf{3}:\left[\mathrm{Co}^{\mathrm{II}}(\mathrm{OTf})\left(\mathrm{N}_{4} \mathrm{Py}\right)\right](\mathrm{OTf}), \mathbf{4}$ : $\left[\mathrm{Co}^{\mathrm{II}}(\mathrm{OTf})(\mathrm{H}-\mathrm{CDPy})\right](\mathrm{OTf})$,

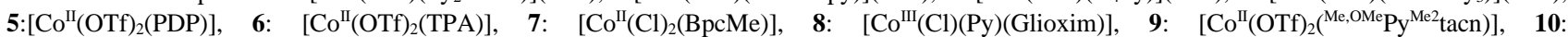

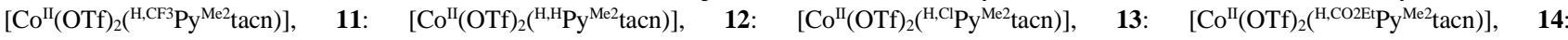
$\left[\mathrm{Co}^{\mathrm{II}}(\mathrm{OTf})_{2}{ }^{\mathrm{H}, \mathrm{NMe}} \mathrm{Py}^{\mathrm{Me} 2}\right.$ tacn $\left.)\right]$ and 15: vitamin B12. Conditions A: Co-Cat $(261 \mu \mathrm{M}, 3 \% \mathrm{~mol}), \mathbf{P C}_{\mathrm{Cu}}(261 \mu \mathrm{M}, 3 \% \mathrm{~mol}), \mathbf{1 6}(17.4 \mu \mathrm{mol}, 8.7 \mathrm{mM})$ in $\mathrm{H}_{2} \mathrm{O}: \mathrm{CH}_{3} \mathrm{CN}: \mathrm{Et}_{3} \mathrm{~N}(6: 4: 0.2 \mathrm{~mL})$ irradiation $(447 \mathrm{~nm})$ for $5 \mathrm{~h}$ at $15^{\circ} \mathrm{C}$ under $\mathrm{N}_{2}$. Yields determined by $\mathrm{GC}$ analysis after workup relative to a calibrated internal standard. Values were average of triplicates and correspond to conversion and [16a and $\mathbf{1 6 b}$ yield].

Selectivity 16 a versus $\mathrm{H}_{2}$ : Hydrogen evolution reaction is usually an overlooked reaction in studies involving photoreduction of organic substrates, but it is essential for further progress in photocatalysed organic reactivity in water when reduced metal complexes are involved. It is well-known that aminopyridine cobalt complexes are efficient catalysts for hydrogen evolution under similar photocatalytic conditions (Figures S.24 - S.25) ${ }^{5 k, 51,18,20}$

Co complexes with aminopyridyl-tacn derived ligands $\left[\mathrm{Co}^{\mathrm{II}}(\mathrm{OTf})_{2}\left({ }^{\mathrm{Y}, \mathrm{X}} \mathrm{Py}^{\mathrm{Me}}\right.\right.$ tacn $\left.)\right]\left(\right.$ series $9-14{ }^{\mathrm{Y}, \mathrm{X}} \mathrm{Py}^{\mathrm{Me}}$ tacn $=1-[(4-\mathrm{X}$ 3,5-Y-2-pyridyl)methyl]-4,7-dimethyl-1,4,7-

triazacyclononane) have been reported among the fastest catalysts for $\mathrm{H}_{2}$ production with TOF, TON, and quantum efficiencies as high as $52000 \mathrm{~h}^{-1}, 9000$, and $9.7 \% \pm 1.0$ for complex $13 .{ }^{20}$ In this regard, the photocatalytic reduction of $\mathbf{1 6}$ was accompanied with the formation of $\mathrm{H}_{2}$ as a by-product, as previously observed for ketone and aldehyde reduction. ${ }^{5 \mathrm{k}}$ Evolved $\mathrm{H}_{2}$ during the reaction was monitored by pressure sensors ${ }^{5 k, 21}$ and quantified by analysis of the reaction headspace using gas chromatography-Thermal Conductivity Detector (GC-TCD, see SI for further details). As expected, the selectivity of the studied Co complexes for substrate $v s$ water reduction (Sel $\mathbf{1 6}_{\mathbf{6}} / \mathbf{H} \mathbf{2}$ calculated as $\mathrm{n}(\mathbf{1 6 a}) /\left(\mathrm{n}\left(\mathbf{H}_{2}\right)\right)$ strongly depends on the ligand scaffold. Under optimized conditions, complex $\mathbf{1}$ is also the most active catalyst for $\mathrm{H}_{2}$ evolution with a Sel $\mathbf{1 6 a}_{\mathbf{H} 2}$ of 1.04 (Table 3 and Figure S.24). Nonetheless, considering the concentrations of water and $\mathbf{1 6}$ in catalysis (ratio $\mathrm{H}_{2} \mathrm{O} / 16$ 19100) the normalized selectivity for the olefin reduction is about 20000 .

The produced $\mathrm{H}_{2}$ was lower with no-tacn based catalysts $(2-8)$, providing an excellent selectivity of $\mathbf{1 6}$ reduction versus $\mathrm{H}_{2}$ but at the expenses of lower yields $\left(\operatorname{Sel}_{16 \mathbf{6} / \mathbf{H} 2}=5.4-9.0\right.$, Figures S.24). For tetradentate tacn-based complexes $9-\mathbf{1 4}$, increasing the electron donating character of the ligand disfavors the $\mathrm{H}_{2}$ evolution, being complex $\mathbf{1 0}$ the most efficient for $\mathrm{H}_{2}$ evolution in the presence of the olefin $\left(\mathrm{Sel}_{\mathbf{1 6} / \mathbf{H} \mathbf{2}}=0.8\right.$ for 10, Figures S.25). ${ }^{51}$ The 15-fold selectivity difference between 9 and $\mathbf{1 0}(p$ $\mathrm{MeO}-$ versus $\left.p-\mathrm{CF}_{3}-\right)$ illustrates the ligand control in the selectivity olefin / water reduction.

Scope of the reaction: With the optimal conditions in hand, we examined the scope of the approach to aromatic olefins.

Monosubstituted styrene derivatives with either electronwithdrawing or donating groups at the arene $(\mathbf{1 6}-\mathbf{2 7})$ are reduced within $5 \mathrm{~h}$ with excellent yields $(73-99 \%)$ (Table 3 ). The reduction of $p$-bromostyrene (22) to $p$-bromoethylbenzene (22a) is obtained in moderate yield (53\%) attributed to the partial formation of the reduced dehalogenated product in $19 \%$ yield. This is consistent with the previously reported reduction of aryl halides giving aryl radicals by visible light-induced electron transfer processes. ${ }^{22}$ In the case of chloride and fluoride substituted olefines at the aromatic ring $(\mathbf{2 3}-\mathbf{2 5})$ the hydrogenation occurred without the loss of the halogen atom (Table 2) ${ }^{23}$ Interestingly, the $\mathrm{CF}_{3}$ substituted aromatic styrene derivative (26) was resilient to the reaction conditions. And substrate $\mathbf{2 7}$, with potentially problematic pyridine coordination, yielded the reduced product with excellent yield (99\%).

1,1-disubstituted olefins. Under optimized reaction conditions the reduction product of 1,1-disubstituted aryl-alkyl olefins (28a - 32a, Table 3) was accompanied with the reductive coupling of two olefins (28b-32b, Table 3, conditions A). We rationalized the formation of homocoupling products as an indication the presence of benzylic radical intermediates. For 1,1-disubstituted aryl-alkyl olefins it can be argued that benzylic radicals are more stable against a single electron reduction surviving long enough to dimerize. As stated above the formation of benzylic radical intermediates has further mechanistic implications that will be discussed in detail in the mechanistic section. 
Table 3. Light-driven reduction of selected aromatic mono- and 1,1-disubstituted olefins.

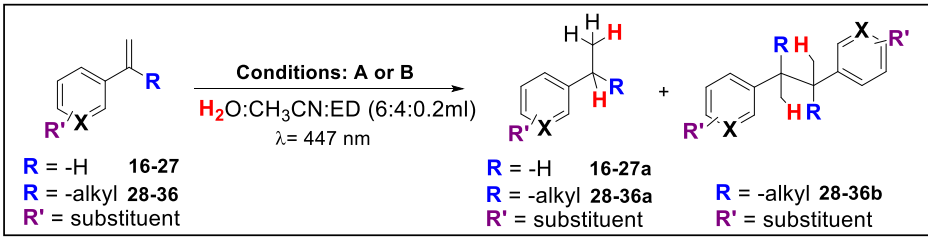

Earth abundant metals Visible light, water/ED as a source of $\mathrm{H}$ Efficient, robust and $\mathrm{O}_{2}$ tolerant

Styrene derivatives and heteroaromatic compounds ${ }^{[a]} \quad$ CONDITIONS A

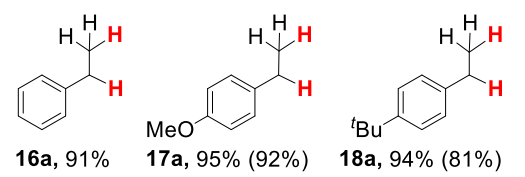

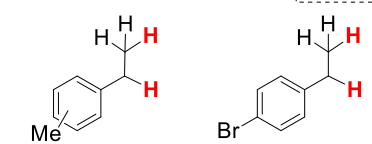

p-Me: $19 a, 99 \%$ $m$-Me: $20 \mathrm{a}, 86 \%$ o-Me: 21a, $86 \%$

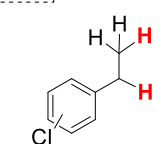

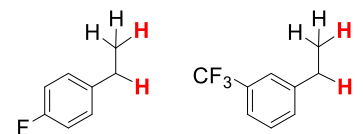

26a, $73 \%$,

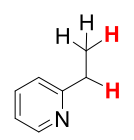

27a, $99 \%$

\section{1,1-disubstituted Ar-olefins ${ }^{[a][b]}$}

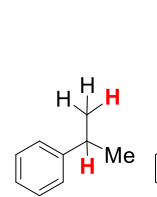

28, $0 \%$

$28 \mathrm{a}, 40 \%$

28b, $45 \%$

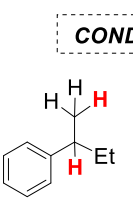

29, $0 \%$

$29 a, 71 \%$

29b. $11 \%$

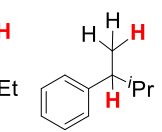

$30,41 \%$

30 a, $58 \%$

30b, $1 \%$

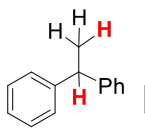

31. $7 \%$

31 a, $83 \%$

31b, $0 \%$

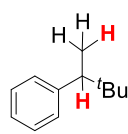

32, $100 \%$

32a, $0 \%$

32a, $0 \%$ 25a, $99 \%$ o-Cl: $24 a, 86 \%,(61 \%)$

\section{CONDITIONS B}

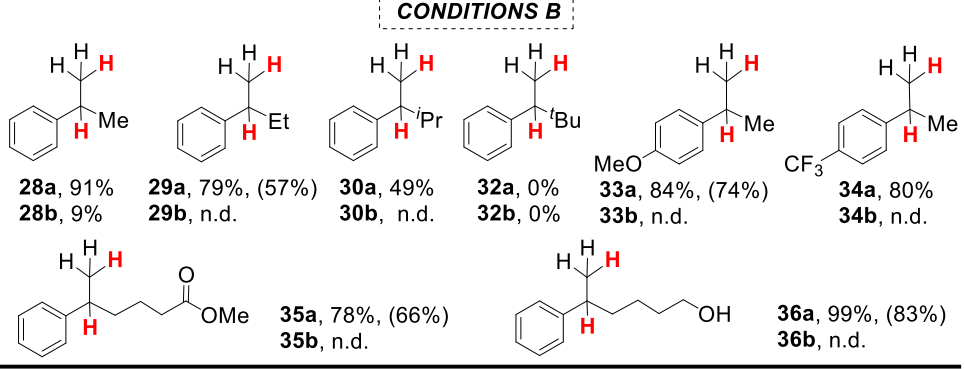

${ }^{[a]}$ Conditions A: $1(3 \mathrm{~mol} \%), \mathbf{P C}_{\mathrm{Cu}}(3 \mathrm{~mol} \%)$, Substrate $(8.7 \mathrm{mM})$ in $\mathrm{H}_{2} \mathrm{O}: \mathrm{CH}_{3} \mathrm{CN}: \mathrm{Et}_{3} \mathrm{~N}(6: 4: 0.2 \mathrm{~mL})$ irradiated $5 \mathrm{~h}(447 \mathrm{~nm})$ at $15{ }^{\circ} \mathrm{C}$ under $\mathrm{N}_{2}$. ${ }^{[b]}$ Conditions B: 1 (6 mol \%), $\mathbf{P C}_{\mathbf{C u}}(6 \mathrm{~mol} \%)$, Substrate $(4.4 \mathrm{mM})$ in $\mathrm{H}_{2} \mathrm{O}: \mathrm{CH}_{3} \mathrm{CN}:{ }^{i} \operatorname{Pr}_{2} \operatorname{EtN}(6: 4: 0.2 \mathrm{~mL})$ irradiated $24 \mathrm{~h}(447 \mathrm{~nm})$ at $-3{ }^{\circ} \mathrm{C}$ under $\mathrm{N}_{2}$. Yields after workup (average of triplicates) determined by GC analysis relative to calibrated internal standard. Isolated yields between parentheses (average of 16 parallel reactions). [a] Yield corresponds to reduced dehalogenated product.

Nevertheless, the presence of benzylic radicals could be formed via a HAT process from the $[\mathrm{Co}-\mathrm{H}]$ intermediate to the less hindered carbon of the olefin, as previously observed for $\mathrm{M}-\mathrm{H}$ species. $^{24}$ This mechanism would then yield reduced homocoupling products. These results are also in agreement with recent reactivity reported on the reduction and homo- and heterocoupling of olefins using silanes as reducing agents; ${ }^{25}$ and on the reactivity of putative $[\mathrm{Co}-\mathrm{H}]$ species with olefins by $\mathrm{J}$. Norton and co-workers, ${ }^{26}$ as well as the recent studies of $\mathrm{M}$ Kojima, S. Matsunaga and co-workers. ${ }^{13}$ Nevertheless, it is well-known that cobalt hydride complexes can undergo HAT to alkenes, and recently showed that can be photo-induced. ${ }^{6 c,} 27$

We note that the yield of the reductive homocoupling product decreased with the alkyl substituent size at the olefin (from -Me to ${ }^{i} \mathrm{Pr}$ ), suggesting also that the size of the substituent affects the product selectivity, as expected for radical couplings. Moreover, the conversion of the -Me, -Et substituted olefins $(\mathbf{2 8 , 2 9})$ was quantitative but not for the ${ }^{i} \operatorname{Pr}$ substituted (30). With the aim to give an explanation to the lack of reactivity we calculated and compared first the redox potentials of the olefins. As expected, the one electron reduction potential of the studied olefins is very negative (See Figures S.20 and S.39). First, the arene parasubstituted olefins $\mathbf{1 7}$ and $\mathbf{1 8}$ with a methoxide and a tert-butyl group, respectively, have redox potentials $\mathrm{E}^{0 /-\mathrm{I}} 1 / 2$ as low as -2.50 , and $-2.45 \mathrm{~V} v s \mathrm{SCE}$. But in both cases, the reaction yields were excellent. Those redox potentials are more negative than the calculated for the 1,1'-disubstituted $\mathrm{Ph},{ }^{i} \mathrm{Pr}$ olefin $(\mathbf{3 0})(-2.40 \mathrm{~V}$, $\mathrm{V} v s \mathrm{SCE})$, suggesting that the lower reactivity for $\mathbf{3 0}$ could be related to steric effects. Indeed, for the bulkier ${ }^{t} \mathrm{Bu}$ - substituted aryl-alkyl olefin (31) there was no conversion. This agrees with a HAT mechanism since it is very sensitive to steric effects. ${ }^{28}$ On the other hand, the catalytic system is inefficient towards the reduction of 1,2-disubstituted styrene derivatives (37 - 41), yielding the trans-cis isomerization as previously reported ${ }^{14}$ and only a trace amount the of reduced product is observed (Table S.12). This could be due to the steric hinderance imposed by the terminal carbon.

In the absence of cobalt catalyst, no olefin reduction neither homocoupling products were detected for the 1,1-disubstituted olefins studied ( $\mathbf{2 8} \mathbf{- 3 1}$, Table S.11). These results agree with the low redox potentials of olefines $\mathbf{2 8}-\mathbf{3 1}$ ( $\mathrm{E}_{\text {red }}-2.36,-2.37$, 2.40 and $-2.29 \mathrm{~V} v s$ SCE, respectively, Figures S.20 and S.39), that are $\geq 690 \mathrm{mV}$ more negative than the $\left[\mathrm{PC}_{\mathbf{C u}}\right]^{\mathbf{0}}$ reduction redox potential $\left(\mathrm{E}\left(\mathrm{PC}_{\mathrm{Cu}}{ }^{1 / 0}\right)=-1.60 \mathrm{~V}\right.$ vs $\left.\mathrm{SCE}\right)$. This evidences that for the studied olefins, the formation of benzylic radicals by Single Electron Transfer (SET) from $\left[\mathbf{P C}_{\mathbf{C u}}\right]^{0}$ is not viable.

At this point, we hypothesized that the selectivity towards olefin reduction could be improved by decreasing the temperature of the reaction. Such a decrease should have an impact on the rate of formation of $[\mathrm{Co}-\mathrm{H}]$ species and then the following formation of benzylic radical species. Preventing the radical accumulation, thus, avoids the formation of homocoupling products since the reaction is second order respect the concentration of radicals (equations 1 and 2, where $v_{\text {rad }}$ and $k_{\text {rad }}$ are the rate and the formation rate constant of the benzylic radical, respectively; $[R]$ and $\left[\mathrm{PC}^{-}\right]$are the concentration of substrate and reduced photoredox catalyst, and $v_{\text {dim }}$ and $k_{\text {dim }}$ are the rate and the formation rate constant of the dimeric product, respectively). Consequently, at higher temperatures $\left(>35^{\circ} \mathrm{C}\right)$ the yield of the reduced product drops in favor of the homocoupling product. In addition, small quantities of trimers or higher order reduced homocoupling products can be also detected by GC-MS, indicating a higher formation of radicals. In contrast, at low temperatures $\left(-3^{\circ} \mathrm{C}\right)$ the dimeric products are negligible (Figure S.26). 
$v_{\mathrm{rad}}=k_{\mathrm{rad}}[\mathrm{R}] \cdot\left[\mathrm{PC}^{\mathrm{n}-1}\right]$

(eq. 1)

$v_{\mathrm{dim}}=k_{\mathrm{dim}}[\mathrm{R}]^{2}$

Further optimization showed that a bulkier electron donor like diisopropylethylamine (DIPEA) favors the selectivity towards the reduced product (Tables S.8), since it avoids formation of by-products with the electron donor due to steric hindrance..$^{29}$ In addition, a finer tuning of the concentration of substrate, catalyst $\mathbf{1}$ and photoredox catalyst $\mathbf{P C}_{\mathbf{C u}}$ (Table S.7 to S.9) allowed to stablish optimum reaction conditions, by increasing the loading of $\mathbf{1}$ and $\mathbf{P C}_{\mathbf{C u}}(6 \mathrm{~mol} \%)$, reducing the substrate concentration (4.4 mM), and using DIPEA at $-3{ }^{\circ} \mathrm{C}$ we achieved excellent selectivity for the reduction of 1,1-disubstituted aromatic olefins (Table S.9 entry 5 and Table 1 conditions B).

$\mathrm{O}_{2}$ tolerance. It is worth noticing that the photocatalytic system maintains its activity even when having $\mathrm{O}_{2}$ in the headspace. The reduction of $\mathbf{1 6}$ and $\mathbf{2 8}$ is accomplished in 91 and $81 \%$ yield, respectively, when the reaction is prepared under air and using non-degassed solvents (Table S.13). We rationalize these results by the capacity of the catalytic system to reduce $\mathrm{O}_{2}$ to $\mathrm{H}_{2} \mathrm{O}$ before reducing the olefins as we observed previously for ketone reduction. ${ }^{5 k, 18,30}$ This contrasts with the high sensitivity of organometallic complexes to $\mathrm{O}_{2}$ when preforming hydrogenation reactions. ${ }^{6 a, 31}$

Deuteration of olefins. We also explored the possibility to obtain deuterated products, with the hypothesis that hydrogen atoms for the reductions come from water. Thus, olefins 17, 18, 23, 28 and $\mathbf{3 6}$ were reduced with the dual $\mathbf{P C}_{\mathbf{C u}} / \mathbf{1}$ catalytic system in a $\mathrm{D}_{2} \mathrm{O}: \mathrm{CH}_{3} \mathrm{CN}$ mixture. We observed nearly quantitative olefin deuteration (see Figures S.41 - S.50). Analytics showed the incorporation of one deuterium atom per carbon atom belonging to the double bond ( $\alpha$ and $\beta$ ) (Scheme 3 ). Moreover, Dlabelling studies of $\alpha$-methylstyrene (28) under catalytic conditions that favor the reduced homocoupling product (high temperature and concentration of substrate) showed the incorporation of only two deuterium atoms - each one at the different methyl group of the coupling product (Figures S.51 and S.52).

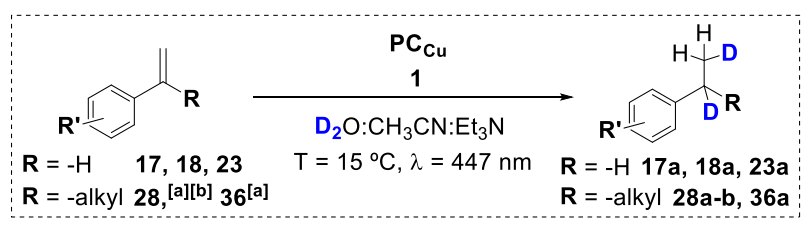

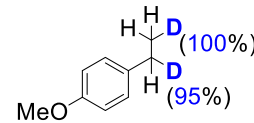

[D]-17a, $89 \%$

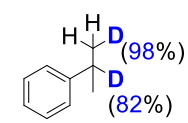

[D]-28a ${ }^{[a]}, 38 \%$ [d]

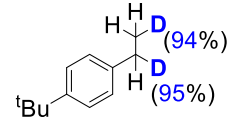

[D]-18a, 54\% [d]

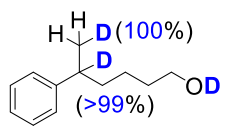

[D]-36a $\mathrm{a}^{[\mathrm{a}]}, 67 \%$ [c]

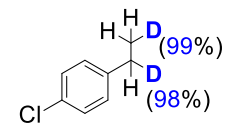

[D]-23a, 33\%[d]

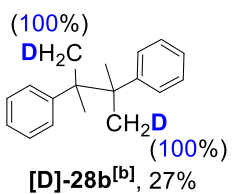

Scheme 3. Deuterium labelling studies of aromatic olefins $(\mathbf{1 7}, \mathbf{1 8}, \mathbf{2 3}$ 28 and 36). Conditions: $1(3 \mathrm{~mol} \%), \mathbf{P C}_{\mathbf{C u}}(3 \mathrm{~mol} \%)$, Substrate $(8.7 \mathrm{mM})$ in $\mathrm{H}_{2} \mathrm{O}: \mathrm{CH}_{3} \mathrm{CN}: \mathrm{Et}_{3} \mathrm{~N}(6: 4: 0.2 \mathrm{~mL})$ irradiated $5 \mathrm{~h}(447 \mathrm{~nm})$ at $15^{\circ} \mathrm{C}$ under $\mathrm{N}_{2}$. ${ }^{\text {a] }}$ Conditions: $1(6 \mathrm{~mol} \%), \mathbf{P C}_{\mathrm{Cu}}(6 \mathrm{~mol} \%)$, Subs. $(4.4 \mathrm{mM})$ in $\mathrm{D}_{2} \mathrm{O}: \mathrm{CH}_{3} \mathrm{CN}:{ }^{i} \mathrm{Pr}_{2} \mathrm{EtN}(6: 4: 0.2 \mathrm{~mL})$ irradiated $(447 \mathrm{~nm})$ for $24 \mathrm{~h}$ at $-3{ }^{\circ} \mathrm{C}$ under $\mathrm{N}_{2}{ }^{\text {[b] }}$ Conditions [a] modifying [Subs.] to $16 \mathrm{mM}$ and $5 \mathrm{~h}$ at 30 ${ }^{\circ} \mathrm{C}$. ${ }^{[c]}$ NMR yield. ${ }^{[d]}$ Low isolated yields were obtained due to the high volatility of the products. Isolated yields (average of 16 reactions). Dinsertion analyzed by NMR.
This agrees with the formation of M-deuteryde species ([Co-D]) that engage a deuterium/hydrogen atom transfer (DAT/HAT) mechanism with the olefin, forming the corresponding benzylic radical, that dimerizes or ends up reduced and protonated, yielding the deuterated product. Moreover, we did not observe double deuteration or H/D scrambling. Therefore, if organometallic cobalt species are formed after the insertion of the $\mathrm{Co}-\mathrm{D} / \mathrm{H}$ in the olefin, the reversibility of the reaction via a beta-hydride elimination is negligible. Thus, it is more likely that benzylic radicals are directly formed via DAT/HAT from Co-D/H. Nevertheless, a metal hydride insertion cannot be fully discarded.

Mechanistic Studies. To get insights into the nature of the active species and the mechanism, we performed kinetics and reactivity studies including D-labelling and radical clocks (Figure 1).

First, kinetic studies in the presence of mercury showed that the photocatalytic activity is not inhibited even in the presence of a large amount of mercury (> 2000 eq vs. 1, Figure 1a). This suggests that the catalysis is not related to metal(0) nanoparticles and, thus, agrees with a homogeneous nature of the active species. We also studied the influence in the reduction rate for 16 in both $\mathrm{H}_{2}$ and $\mathrm{N}_{2}$ atmosphere (Figure 1b). The kinetic traces were identical regardless the atmosphere used, indicating that the source of hydrogen in the reduced products does not come from the $\mathrm{H}_{2}$ generated under photocatalytic conditions. Indeed, both $\mathrm{H}_{2}$ evolution and olefin reduction are competing pathways that share a common intermediate, since with catalyst $\mathbf{1}$ the $\mathrm{H}_{2}$ produced decreased at higher concentrations of styrene (Figure S.27).

As introduced in the previous section, the exchange of $\mathrm{H}_{2} \mathrm{O}$ by $\mathrm{D}_{2} \mathrm{O}$ led to the formation of deuterated olefins with exclusive deuteration on the carbons of the olefin and to the limit of the detection only two deuterium atoms were introduced one in each of the olefinic carbon atoms (Scheme 3 and SI section 13 for NMR analyses). The absence of scrambling and double deuterium insertions indicates that regardless the mechanistic path the reaction is not reversible. On the other hand, when we employed the 1,2 disubstituted olefin 41, we did not observe deuterium insertion (Figures S.53 - S.54), indicating that although and isomerization takes place, it is most likely to proceed through a photochemically generated exited state without the intervention of $[\mathrm{Co}-\mathrm{H}]$ insertion-elimination steps. ${ }^{15}$

Experiments with radical clocks were performed to evaluate the formation of benzyl radicals via a HAT mechanism as already suggested by the formation of dimeric products. Olefins containing a 2-aryl-cyclopropyl moiety at the $\alpha$-position are commonly used as probes for the formation of radicals in organic transformations..$^{15,} 32$ These radical clocks are very convenient because if a radical is generated in the benzylic position, it will trigger the cyclopropane ring opening with a high rate constant. For the (1-(2phenylcyclopropyl)vinyl)benzene (42) cyclopropane ring opening is about $10^{8} \mathrm{~s}^{-1} .{ }^{33}$ Moreover, the presence of an aromatic group at the olefin is necessary to stabilized the radical as benzylic after the cyclopropane ring-opening. Without the stabilizing group, the resulting product from the cyclopropane ring-opening is endergonic and could yield wrong conclusions (Figure S.40). ${ }^{33}$ Under catalytic conditions the reduction of $\mathbf{4 2}$ only yields the ring-opened product $(\mathbf{4 2 b})$ without detection of 42a (Scheme 4). 

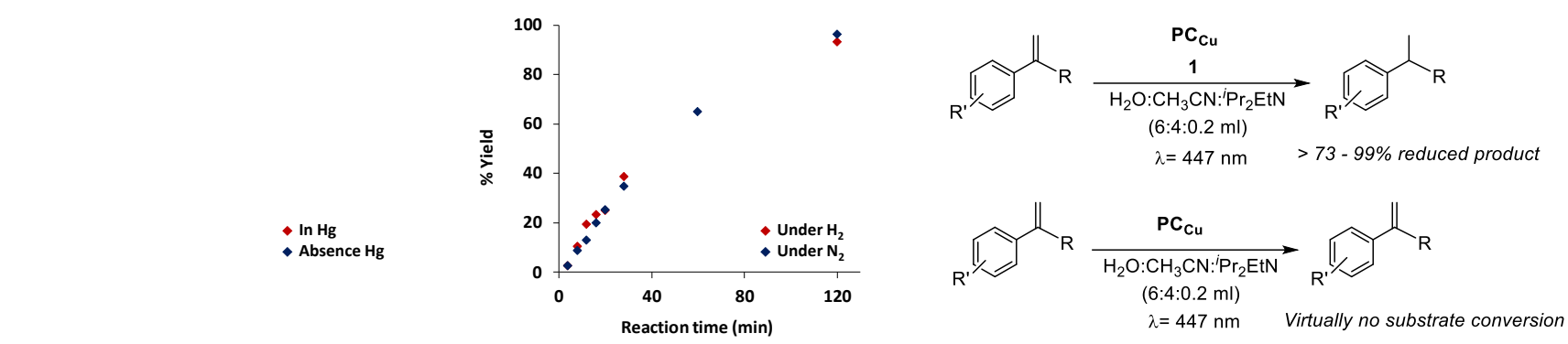

d) Electronic and Steric effects in the reduction of mono- and 1,1-disubstituted olefins

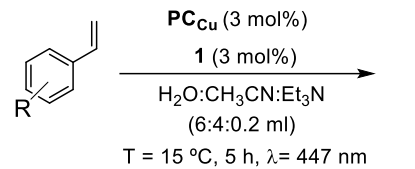<smiles>CCc1cc[R]cc1</smiles>
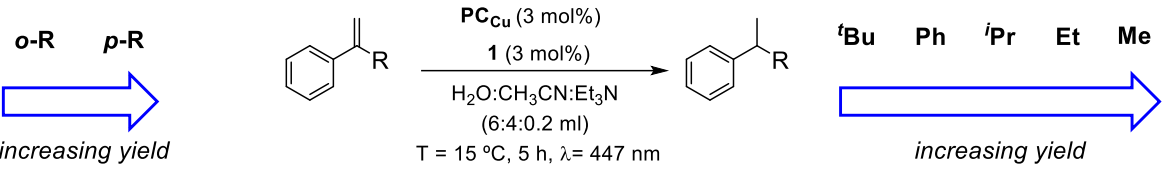

e) Deuterium labelling studies with mono- and 1,1-disubstituted olefins

f) Deuterium labelling studies with 1,2-disubstituted olefins
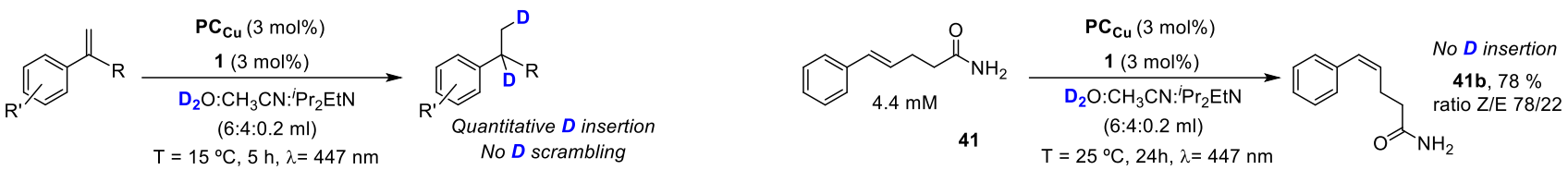

Figure 1. Mechanistic studies. Formation of 16a in a) the absence (red diamonds) and presence of $\mathrm{Hg}(0)$ ( $>2000$ eq.) (blue diamonds); and in b) $\mathrm{H}_{2}$ (red diamonds) or $\mathrm{N}_{2}$ (blue diamonds) atmosphere. c) Experiments with and without complex 1. d) Steric effects in olefin reduction. Deuterium labelling studies of mono- and 1,1-disubstituted olefins (e) and 1,2-disubstituted olefin 41 (f, Z/E ratio analyzed by NMR.). See experimental section 3 for the procedure details.

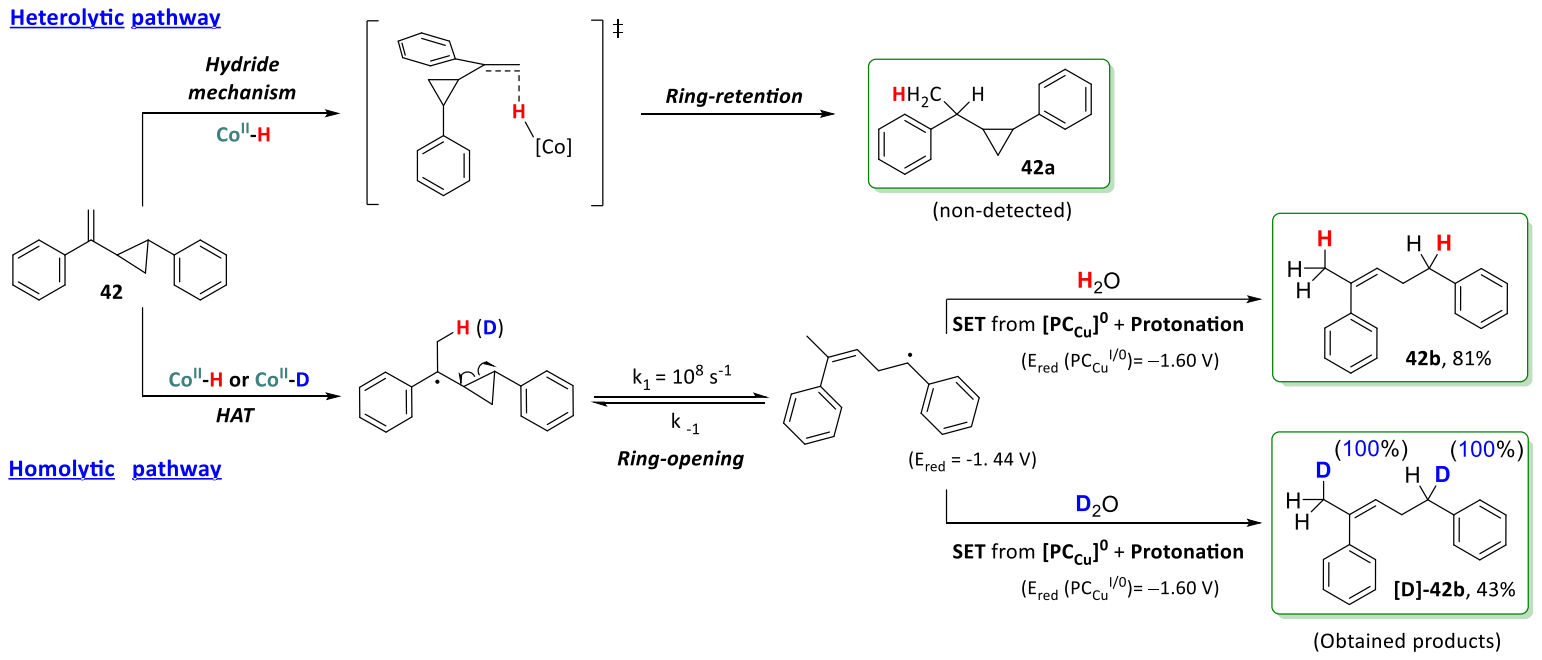

Scheme 4. Two possible reduction pathways for (1-(2-phenylcyclopropyl)vinyl)benzene (42).

When the reaction was performed in $\mathrm{D}_{2} \mathrm{O}$, a quantitative $\mathrm{D}$ insertion in the $\beta$ and benzylic positions was obtained ([D]-42b, confirmed by NMR and MS studies, see Figures S.55 - S.61). In the lack of the cobalt catalyst $\mathbf{1}$, no ring-opened products were detected; fully recovering the substrate after irradiation. Both 42b and [D]-42b can be formed via initial HAT (or DAT) from a $[\mathrm{Co}-\mathrm{H}]$ (or $[\mathrm{Co}-\mathrm{D}]$ ) followed by ring-opening and rearrangement to the most stable radical (Scheme 4).

Mechanistic Discussion. Mechanisms in Scheme 5 were proposed considering the collection of experimental results. It is well-stablished that light irradiation $(447 \mathrm{~nm})$ of
$[\mathrm{Cu} \text { (bathocuproine)(xantphos) }]^{+} \quad\left(\left[\mathbf{P C}_{\mathbf{C u}}\right]^{+}\right)$leads to the formation of the $*\left[\mathrm{PC}_{\mathbf{C u}}\right]^{+}$excited state, which is reductively quenched in presence of an excess of aliphatic amine. ${ }^{17} \mathrm{We}$ used $\mathrm{Et}_{3} \mathrm{~N}$ or ${ }^{i} \mathrm{Pr}_{2} \mathrm{EtN}$ as quenchers. The reaction then yields the oneelectron reduced $\left[\mathrm{PCCu}^{0}\right.$ species $\left(\mathrm{E}\left(\mathrm{PC}_{\mathrm{Cu}}{ }^{\mathrm{I} / 0}\right)=-1.60 \mathrm{~V}\right.$ vs $\mathrm{SCE}){ }^{34}$ The reduction potential of employed olefins are in the range of -2.1 to $-2.6 \mathrm{~V} v s \mathrm{SCE}^{15}$ (Figure S.39 for the theoretical values). Therefore, based on the thermodynamics of the process, the direct reduction by the singly reduced species $\left[\mathbf{P C}_{\mathbf{C u}}\right]^{0}$ could be discarded ( $\Delta \mathrm{G}$ of the reaction is endergonic by 12 to 23 $\mathrm{kcal} \cdot \mathrm{mol}^{-1}$ depending of the olefine).$^{5 \mathrm{k}}$ 

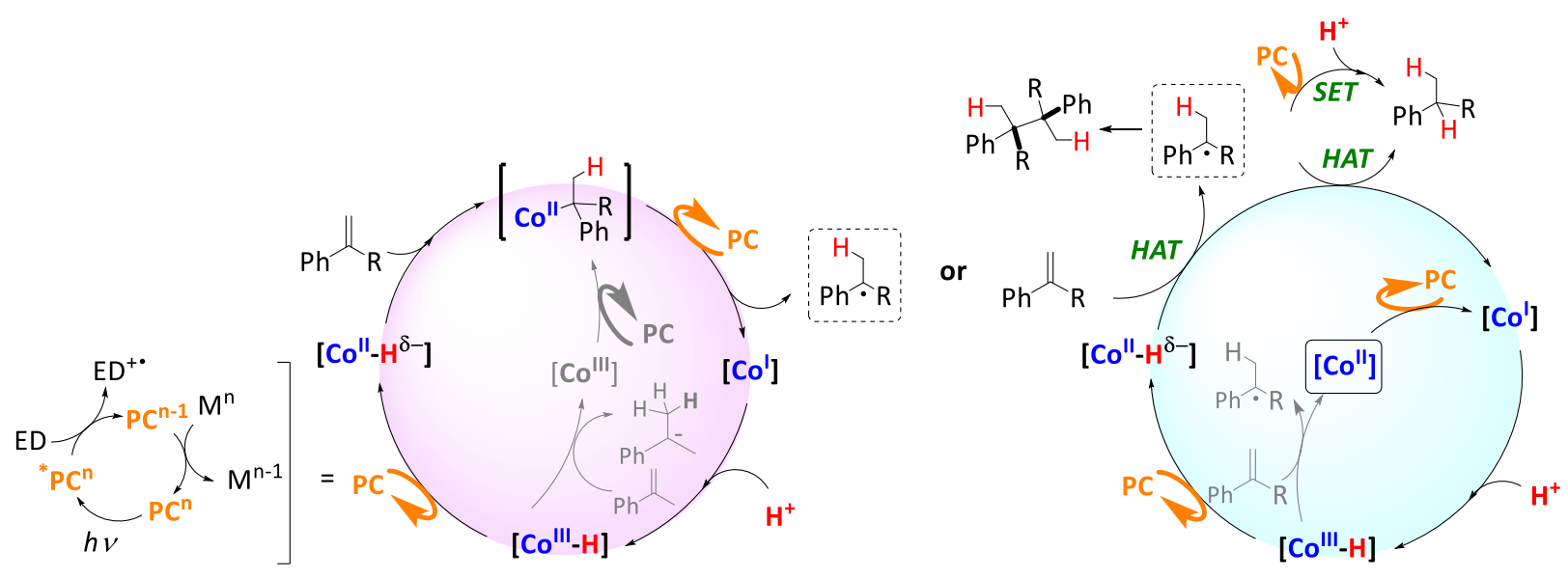

Scheme 5. Possible mechanistic scenarios for the reduction of aromatic olefins by the light-driven dual-copper-cobalt catalytic system in aqueous media. The highlighted $\left[\mathbf{C o}^{\mathrm{II}}\right]$ intermediate indicates the beginning of the catalytic cycle. Acronym stand for $\mathbf{P C}=$ photoredox catalyst; $\mathbf{E D}=$ electron donor; SET $=$ single electron transfer and HAT $=$ hydrogen atom transfer.

This is supported by the lack of reduced, dimerized or ringopening product formed when radical clock $42\left(\mathrm{E}\left(42^{0 /-}\right)=-2.36\right.$ $\mathrm{V} v s$ SCE) was tested when complex $\mathbf{1}$ it is not present in the solution. However, $\left[\mathbf{P C}_{\mathbf{C u}}\right]^{\mathbf{0}}$ is reductive enough to reduce complex $1\left(\mathrm{E}\left(\mathrm{Co}^{\mathrm{II} /}\right)=-1.15 \mathrm{~V}\right.$ vs $\left.\mathrm{SCE}\right)$ affording $\mathrm{Co}^{\mathrm{I}}$ species. ${ }^{18}$ We previously studied the formation of similar $\mathrm{Co}^{\mathrm{I}}$ species under photo- and electrochemical conditions. ${ }^{20,35}$ These lowvalent intermediates can be protonated by water to form a putative $\left[\mathrm{Co}^{\mathrm{III}}-\mathrm{H}\right]$, which under such reducing photochemical conditions, can be converted into $\left[\mathrm{CO}^{\mathrm{II}}-\mathrm{H}\right]$ species. ${ }^{5 \mathrm{k}, 20}$ On the other hand, it is interesting that the reaction order found in olefin is close to zero (Figure S.27). The fact that olefin concentration does not modify the reaction rate is consistent with our previous studies in hydrogen evolution and the reduction of ketones and aldehydes. ${ }^{5 \mathrm{k}, 20} \mathrm{We}$ interpreted this result as the formation of the $[\mathrm{Co}-\mathrm{H}]$ complex as rate determining. Moreover, as discussed above, this $[\mathrm{Co}-\mathrm{H}]$ is a common intermediate for both $\mathrm{H}_{2}$ evolution and olefin reduction.

The formation of homocoupling products and the isotopic Dlabelling pattern observed, together with radical clock experiments support that the reaction proceeds via the formation of benzylic radical species. As explained above, the most likely pathway to form the benzylic radicals is by a HAT from [Co ${ }^{\mathrm{II}}$ $\mathrm{H}]$ to the $\beta$ carbon of the olefin. Whereas a potential metal hydride insertion is less likely. Despite cannot be completely ruled out, since no doubly-deuterated terminal-carbons in the reduced products were detected, which means that beta-hydride elimination is not occurring (Scheme 5a). Then, the fastest and most likely scenario is that benzylic radicals undergo a reduction $\left(\mathrm{E}_{\text {red }}{ }^{\text {theor }}=-1.44\right.$ to $\left.-1.69 \mathrm{~V} v s \mathrm{SCE}\right)$ by $\left[\mathbf{P C}_{\mathrm{Cu}}\right]^{0}(\mathrm{E}=-1.60 \mathrm{~V}$ vs SCE) which after subsequent protonation leads the alkane (Scheme $5 b$ ). We discard the HAT from the oxidized amine because the deuteration of the benzylic position is virtually quantitative.

Mechanistically designed ketone/olefin reduction selectivity. The postulated HAT mechanism for olefin reduction (Scheme $5 b)$ implies that the selectivity could be modulated against functional groups that are reduced via a different mechanism such as SET. This is the case for our previously reported reduction of aromatic ketones using the dual catalytic system. ${ }^{5 \mathrm{k}}$

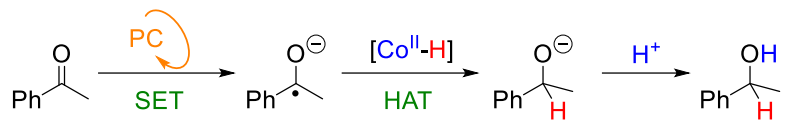

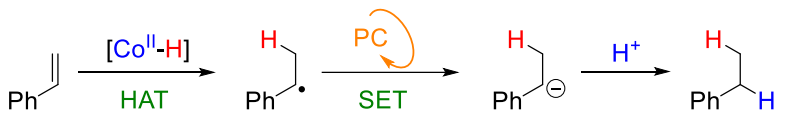

Scheme 6. Different substrate-dependent mechanisms for the observed selectivity. KRA stands for ketyl radical anion and PC for the photoredox cycle.

To test our hypothesis, we used styrene (16) and acetophenone (43) as competing substrates. We previously determined, that under equivalent photocatalytic conditions, $\mathbf{4 3}$ is reduced to 1phenylethanol via a SET mechanism from $\left[\mathbf{P C}_{\mathbf{C u}}\right]^{\mathbf{0}}$ yielding the ketyl radical anion (KRA) as intermediate $\left(\mathrm{E}_{\text {red }}=-1.65 \mathrm{~V} v s\right.$ $\mathrm{SCE}){ }^{5 \mathrm{k}, 5 \mathrm{l}}$ Then the generated KRA is trapped by the [Co-H] to form the reduced product via HAT (Scheme 6). Therefore, it should be possible to differentiate the KRA formation via SET from the HAT mechanism of the olefin designing rationally the photocatalytic conditions.

This rationalization suggests that the counterintuitive idea of increasing the redox potential of the photoredox catalyst, should make the catalytic system more selective. For instance, under more reducing conditions a SET mechanism should be favored, and therefore, the reduction of the ketone would be preferent, while the opposite would favor otherwise.

First, when similar catalytic conditions to the reported for the selective reduction of aromatic ketones $v s$ aliphatic aldehydes ${ }^{5 \mathrm{k}}$ were used (1 (1 mol\%), $\mathbf{P C}_{\mathbf{C u}}(1.5 \mathrm{~mol} \%)$, total substrates (16.5 $\mathrm{mM}, 1: 1)$ in $\mathrm{H}_{2} \mathrm{O}: \mathrm{CH}_{3} \mathrm{CN}: \mathrm{Et}_{3} \mathrm{~N}(6: 4: 0.2 \mathrm{~mL})$ irradiated for $4 \mathrm{~h}$ at $25{ }^{\circ} \mathrm{C}$ under $\mathrm{N}_{2}$ ), acetophenone (43) was preferentially

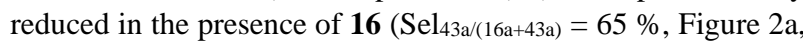
Table S.14 and Figure S.28). Then, we modified the reaction conditions to test the hypothesis of favor either the SET to 43 or the HAT to 16. For stronger reducing conditions to favor the SET, we sequentially increased the reduction potential, concentration of the PC and the light irradiation intensity. Moreover, we also decreased the concentration of complex $\mathbf{1}$ to disfavor the HAT process. To our delight, an improvement in the selectivity was observed by using ${ }^{\text {NMe } 2} \mathbf{P} \mathbf{C}_{\text {Ir }}$ instead of $\mathbf{P C} \mathbf{C u}$ (from 65 to $72 \%$ selectivity). 


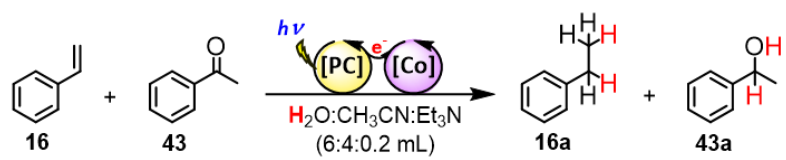

a) Tunning of conditions for ketone reduction selectivity

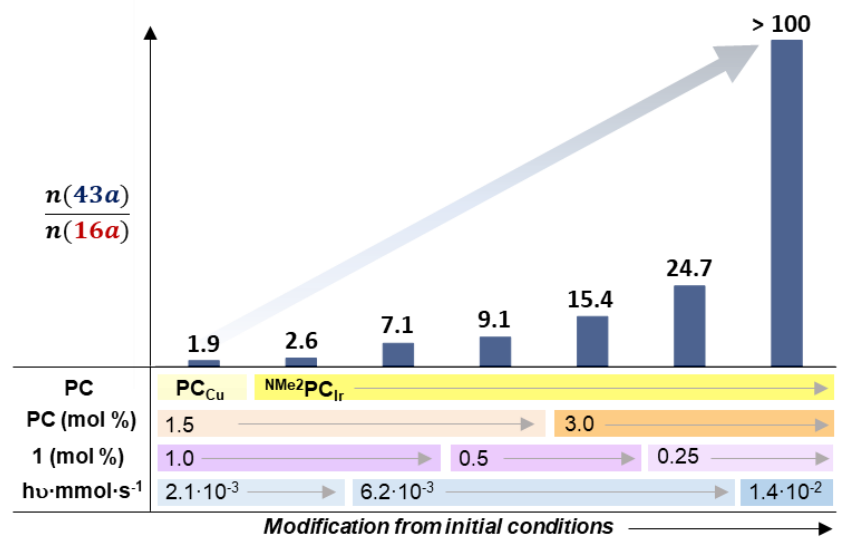

c) Optimised conditions for ketone reduction selectivity

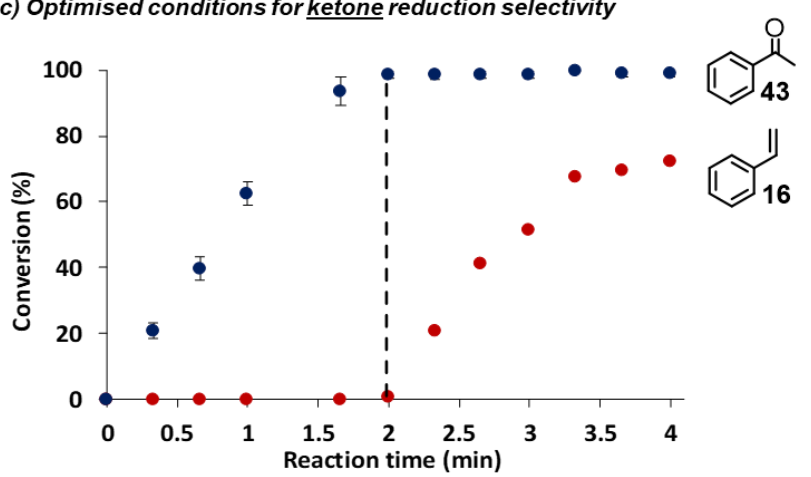

b) Tunning of conditions for olefin reduction selectivity

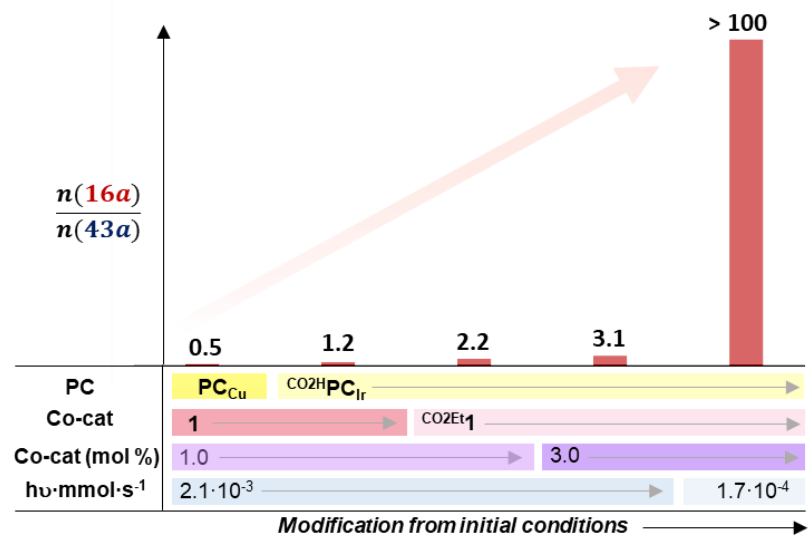

d) Optimised conditions for olefin reduction selectivity

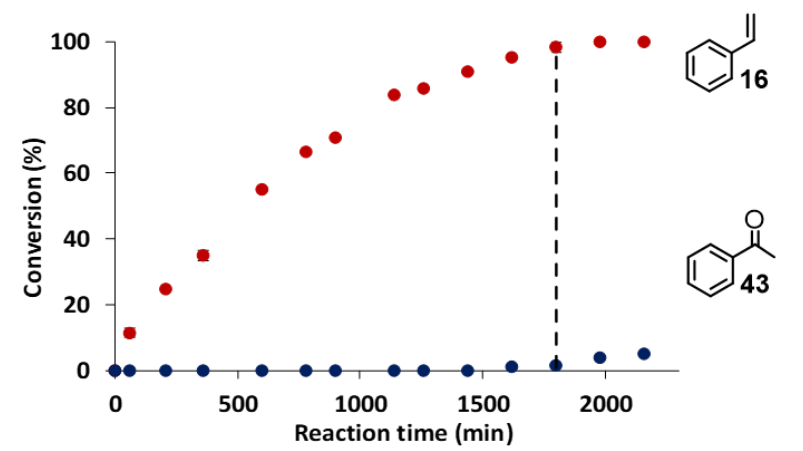

Figure 2. Competition studies between styrene (13a) and acetophenone (9a). Conditions: (top) $\mathbf{1}$ (0.25 $\left.\mathrm{mol}^{2}\right)$, ${ }^{\mathrm{NMe} 2} \mathbf{P C} \mathbf{I r}(3 \mathrm{~mol} \%)$, total substrate concentration $(16.5 \mathrm{mM})$ in $\mathrm{H}_{2} \mathrm{O}: \mathrm{CH}_{3} \mathrm{CN}: \mathrm{Et}_{3} \mathrm{~N}(3: 2: 0.1 \mathrm{~mL})$ mixture, irradiated at $447 \mathrm{~nm}\left(7 \mathrm{LED}\right.$ at $700 \mathrm{~mA}, 1.44 \cdot 10^{-2} \mathrm{mmol} \cdot \mathrm{hv} \cdot \mathrm{s}^{-1}$ of photons $\left.{ }^{20}\right)$ for 4 min at $25{ }^{\circ} \mathrm{C}$ under $\mathrm{N}_{2}$. (Bottom): ${ }^{\text {Co2Et } 1 ~(3 ~ m o l \%), ~}{ }^{{ }^{C 2} \mathrm{H}_{\mathbf{P C}}}$ (1.5 mol\%), total substrate concentration $(16.5 \mathrm{mM})$ in $\mathrm{H}_{2} \mathrm{O}: \mathrm{CH}_{3} \mathrm{CN}: \mathrm{Et}_{3} \mathrm{~N}(3: 2: 0.1 \mathrm{~mL})$ mixture, irradiated at $447 \mathrm{~nm}\left(1 \mathrm{LED}\right.$ at $50 \mathrm{~mA} 1.67 \cdot 10^{-4} \mathrm{mmol} \cdot \mathrm{hv} \cdot \mathrm{s}^{-1}$ of photons $\left.{ }^{20}\right)$ for $36 \mathrm{~h}(2160 \mathrm{~min})$ at $25^{\circ} \mathrm{C}$ under $\mathrm{N}_{2}$. The black dotted line indicates where substrates 16 (top) and 22 (bottom) start reacting.

Further improvement was obtained by increasing the light intensity up to $6.2 \cdot 10^{-3} \mathrm{mmol} \cdot \mathrm{hv} \cdot \mathrm{s}^{-1}$ vs the normal $2.1 \cdot 10^{-3}$ $\mathrm{mmol} \cdot \mathrm{hv} \cdot \mathrm{s}^{-1},{ }^{20}$ which presumably increased the concentration of the reduced photoredox catalyst $\left.\left({ }^{\mathrm{NMe} 2} \mathbf{P C} \mathbf{C}_{\text {Ir }}\right]^{0}\right)$ and, thus, accelerating the SET (from 72 to $88 \%$ Table S.14 and Figures S.29 - S.30). In contrast, the effect of complex 1 concentration was minor (from 88 to $90 \%$ ). As a result, $100 \%$ selectivity for ketone 43 reduction (in $2 \mathrm{~min}$ ) was obtained in presence of styrene 16 using ${ }^{\text {NMe2 }} \mathbf{P C}$ Ir $\left(3 \mathrm{~mol} \%, \mathrm{E}_{1 / 2}\left(\mathrm{Ir}^{\mathrm{III} / \mathrm{II}}\right)=-1.80 \mathrm{~V} v \mathrm{~s}\right.$ $\mathrm{SCE})$, complex $1\left(0.25 \mathrm{~mol} \%, \mathrm{E}\left(\mathrm{Co}^{\mathrm{II} / \mathrm{I}}\right)=-1.15 \mathrm{~V}\right.$ vs SCE$)$ and irradiating at higher light intensity $\left(1.4 \cdot 10^{-2} \mathrm{mmol} \cdot \mathrm{hv} \cdot \mathrm{s}^{-1}\right)$ (Figure 2, $a$ and $c$ ).

To favor the HAT, we modified the reaction conditions to make them less reducing. First, we used the less reductive photoredox catalyst ${ }^{{ }^{C O 2 H}} \mathrm{PC}_{\mathrm{Ir}}\left(\mathrm{E}_{1 / 2}\left(\mathrm{Ir}^{\mathrm{III} / \mathrm{II}}\right)=-1.01 \mathrm{~V}\right.$ vs $\left.\mathrm{SCE}\right)$ and the selectivity for styrene reduction increased in $20 \%$ (Figure $2 b$, Table S.15 and Figure S.35). Likewise, using a less reductive Co catalyst $\left[\left(\mathrm{Co}^{\mathrm{II}}(\mathrm{OTf})\left({ }^{\mathrm{H}, \mathrm{CO} 2 \mathrm{Et}} \mathrm{Py}_{2}{ }^{\mathrm{Ts}} \operatorname{tacn}\right)\right]\left({ }^{\mathrm{CO} 2 \mathrm{Et}} \mathbf{1}, \mathrm{E}\left(\mathrm{Co}^{\mathrm{I} / /}\right)=-\right.\right.$ $0.96 \mathrm{~V}$ vs SCE) the selectivity also improved in $14 \%$. Then, we increased the ${ }^{{ }^{C O 2 E t} \mathbf{1}}$ concentration with the idea to increase [Co$\mathrm{H}]$ and thus the HAT product $\left(\operatorname{Sel}_{16 a}(43 \mathrm{a}+16 \mathrm{a})=76 \%\right.$, Figures S.36 and S.37).
Finally, lowering the light intensity $\left(1.7 \cdot 10^{-4} \mathrm{mmol} \cdot \mathrm{hv} \cdot \mathrm{s}^{-1}\right), \mathbf{1 6}$ was selectively reduced over $\mathbf{4 3}$ with $100 \%$ selectivity (Figure 2 $\mathrm{d}$, and Table S.15). GC monitoring of the reactions showed that 16 was consumed and converted to 16a, whereas 43 remained virtually intact and vice versa (Figure $2 \mathrm{c}$ and $\mathrm{d}$ ).

The observed selectivity agrees with the existence of two competitive mechanistic scenarios involving: i) SET + HAT for substrates than can be directly reduced such as acetophenone and ii) HAT for substrates with low reduction potentials that cannot be directly reduced by one electron such as aromatic olefins.

\section{CONCLUSIONS}

We developed a dual cobalt-copper catalytic system capable to reduce aromatic olefins under simple operational conditions, just using $\mathrm{H}_{2} \mathrm{O}$ and an amine $\left(\mathrm{Et}_{3} \mathrm{~N}\right.$ or $\left.{ }^{i} \operatorname{Pr}_{2} \mathrm{EtN}\right)$ as the source of hydrides and visible light as the driving force. Our mechanistic studies based on reactivity, ligand control, selectivity, labelling studies and reactivity with radical clocks support a well-defined cobalt hydride as the intermediate responsible for the reductions, most likely through a HAT mechanism, discarding free radical diffusion as main pathway. These results show that the selectivity of metal hydrides in basic media can be controlled 
and directed to the reduction of organic functionalities. For this reason, we envision that other readily available $\mathrm{H}_{2} \mathrm{O}$ reduction catalysts could be also found active in the reduction of other functional groups and more complex structures. These results pave the way for the development of selective organic reductions and solar-chemicals generation by artificial catalytic systems that operate entirely with earth-abundant elements, using visible light as the driving force and $\mathrm{H}_{2} \mathrm{O}$ as a source of hydrides.

\section{ASSOCIATED CONTENT}

Supporting Information. Synthesis and characterization of ligands, and catalysts and optimization screening and selectivity photocatalytic studies. This material is available free of charge via the Internet at http://pubs.acs.org.

\section{AUTHOR INFORMATION}

\section{Corresponding Author \\ * Julio Lloret-Fillol. jlloret@iciq.es}

\section{ACKNOWLEDGMENT}

We would like to thank the European Commission for the ERCCG-2014-648304 (J.Ll.-F) project. The Spanish Ministry of Science is acknowledged for a FPU fellowship to C.C. and A.C. and Juan de la Cierva contract to A.C. We also thank Catexel for a generous gift of tritosyl-1,4,7-triazacyclononane. The financial support from ICIQ Foundation and CELLEX Foundation through the CELLEX-ICIQ high throughput experimentation platform. We also thank CERCA Programme (Generalitat de Catalunya) for financial support. We thank Dr. Ferran Acuña-Parés for fruitful discussions.

\section{REFERENCES}

1. (a) Barber, J.; Tran, P. D., From natural to artificial photosynthesis. J. R. Soc. Interface 2013, 10 (81), 20120984; (b) Galian, R. E.; PérezPrieto, J., Catalytic processes activated by light. Energy Environ. Sci. 2010, 3 (10), 1488; (c) Stephenson, C. R.; Yoon, T. P., Enabling Chemical Synthesis with Visible Light. Acc. Chem. Res. 2016, 49 (10) 2059-2060; (d) Zhang, B.; Sun, L., Artificial photosynthesis: opportunities and challenges of molecular catalysts. Chem. Soc. Rev. 2019, 48 (7), 2216-2264.

2. (a) Lewis, N. S.; Nocera, D. G., Powering the planet: chemical challenges in solar energy utilization. Proc. Natl. Acad. Sci. U. S. A. 2006, 103 (43), 15729-35; (b) Cook, T. R.; Dogutan, D. K.; Reece, S. Y.; Surendranath, Y.; Teets, T. S.; Nocera, D. G., Solar Energy Supply and Storage for the Legacy and Nonlegacy Worlds. Chem. Rev. 2010, 110 , 6474-6502; (c) Andreiadis, E. S.; Chavarot-Kerlidou, M.; Fontecave, M.; Artero, V., Artificial photosynthesis: from molecular catalysts for light-driven water splitting to photoelectrochemical cells. Photochem Photobiol 2011, 87 (5), 946-64; (d) Dalle, K. E.; Warnan, J.; Leung, J. J.; Reuillard, B.; Karmel, I. S.; Reisner, E., Electro- and Solar-Driven Fuel Synthesis with First Row Transition Metal Complexes. Chem. Rev. 2019, 119 (4), 2752-2875.

3. (a) Han, Z.; Eisenberg, R., Fuel from water: the photochemical generation of hydrogen from water. Acc. Chem. Res. 2014, 47 (8), 2537-44; (b) Thoi, V. S.; Sun, Y.; Long, J. R.; Chang, C. J., Complexes of earth-abundant metals for catalytic electrochemical hydrogen generation under aqueous conditions. Chem. Soc. Rev. 2013, 42 (6), 2388-400; (c) Zee, D. Z.; Chantarojsiri, T.; Long, J. R.; Chang, C. J., Metal-polypyridyl catalysts for electro- and photochemical reduction of water to hydrogen. Acc. Chem. Res. 2015, 48 (7), 2027-36; (d) Kaeffer, N.; Chavarot-Kerlidou, M.; Artero, V., Hydrogen evolution catalyzed by cobalt diimine-dioxime complexes. Acc. Chem. Res. 2015, 48 (5), 1286-95; (e) Queyriaux, N.; Jane, R. T.; Massin, J.; Artero, V.; Chavarot-Kerlidou, M., Recent Developments in Hydrogen Evolving Molecular Cobalt(II)-Polypyridyl Catalysts. Coord. Chem. Rev. 2015, 304-305, 3-19.

4. (a) Appel, A. M.; Bercaw, J. E.; Bocarsly, A. B.; Dobbek, H.; DuBois, D. L.; Dupuis, M.; Ferry, J. G.; Fujita, E.; Hille, R.; Kenis, P. J.; Kerfeld, C. A.; Morris, R. H.; Peden, C. H.; Portis, A. R.; Ragsdale, S. W.;
Rauchfuss, T. B.; Reek, J. N.; Seefeldt, L. C.; Thauer, R. K.; Waldrop, G. L., Frontiers, opportunities, and challenges in biochemical and chemical catalysis of $\mathrm{CO}_{2}$ fixation. Chem. Rev. 2013, 113 (8), 6621-58; (b) Qiao, J.; Liu, Y.; Hong, F.; Zhang, J., A review of catalysts for the electroreduction of carbon dioxide to produce low-carbon fuels. Chem. Soc. Rev. 2014, 43 (2), 631-75; (c) Costentin, C.; Robert, M.; Saveant, J. M., Catalysis of the electrochemical reduction of carbon dioxide. Chem. Soc. Rev. 2013, 42 (6), 2423-36; (d) Boddu, S.; Nishanthi, S. T.; Kailasam, K., Visible-Light Heterogeneous Catalysts for Photocatalytic $\mathrm{CO} 2$ Reduction. In Visible Light-Active Photocatalysis, 2018; pp 421-446; (e) Franco, F.; Fernández, S.; Lloret-Fillol, J., Advances in the electrochemical catalytic reduction of CO2 with metal complexes. Curr. Opin. Electrochem 2019, 15, 109117.

5. (a) Palmisano, G.; Augugliaro, V.; Pagliaro, M.; Palmisano, L., Photocatalysis: a promising route for 21 st century organic chemistry. Chem. Commun. 2007, (33), 3425-37; (b) Choudhury, S.; Baeg, J. O.; Park, N. J.; Yadav, R. K., A photocatalyst/enzyme couple that uses solar energy in the asymmetric reduction of acetophenones. Angew. Chem. Int. Ed. 2012, 51 (46), 11624-8; (c) Lee, S. H.; Kim, J. H.; Park, C. B., Coupling Photocatalysis and Redox Biocatalysis Toward Biocatalyzed Artificial Photosynthesis. Chem. Eur. J. 2013, 19, 4392 4406; (d) Mifsud, M.; Gargiulo, S.; Iborra, S.; Arends, I. W.; Hollmann, F.; Corma, A., Photobiocatalytic chemistry of oxidoreductases using water as the electron donor. Nat Comm. 2014, 5, 3145; (e) Kim, J. H.; Nam, D. H.; Park, C. B., Nanobiocatalytic assemblies for artificial photosynthesis. Curr. Opin. Biotechnol. 2014, 28, 1-9; (f) Liu, J.; Huang, J.; Zhou, H.; Antonietti, M., Uniform graphitic carbon nitride nanorod for efficient photocatalytic hydrogen evolution and sustained photoenzymatic catalysis. ACS Appl. Mater. Interf. 2014, 6 (11), 8434-40; (g) Bachmeier, A.; Murphy, B. J.; Armstrong, F. A., A multi-heme flavoenzyme as a solar conversion catalyst. J. Am. Chem. Soc. 2014, 136 (37), 12876-9; (h) Andreiadis, E. S.; Chavarot-Kerlidou, M.; Fontecave, M.; Artero, V., Artificial photosynthesis: from molecular catalysts for light-driven water splitting to photoelectrochemical cells. Photochem. Photobiol. 2011, 87 (5), 94664; (i) Macia-Agullo, J. A.; Corma, A.; Garcia, H., Photobiocatalysis: the power of combining photocatalysis and enzymes. Chem. Eur. J. 2015, 21 (31), 10940-59; (j) De Luna, P.; Hahn, C.; Higgins, D.; Jaffer, S. A.; Jaramillo, T. F.; Sargent, E. H., What would it take for renewably powered electrosynthesis to displace petrochemical processes? Science 2019, 364 (6438), eaav3506; (k) Call, A.; Casadevall, C.; Acuna-Pares, F.; Casitas, A.; Lloret-Fillol, J., Dual cobalt-copper lightdriven catalytic reduction of aldehydes and aromatic ketones in aqueous media. Chem. Sci. 2017, 8 (7), 4739-4749; (I) Call, A.; LloretFillol, J., Enhancement and control of the selectivity in light-driven ketone versus water reduction using aminopyridine cobalt complexes. Chem. Commun. 2018, 54 (69), 9643-9646; (m) Casadevall, C. Mechanistic studies of water oxidation catalyzed by homogeneous iron and ruthenium complexes and light-driven organic reductions with a dual cobalt/copper catalytic system. Universitat Rovira i Virgili, 2019; (n) Lloret-Fillol, J.; Casitas, A.; Call, A.; Casadevall, C. Photocatalytic Reduction Process and catalytic composition used in the process, 2017, PCT/ES2017/070314.

6. (a) Alig, L.; Fritz, M.; Schneider, S., First-Row Transition Metal (De)Hydrogenation Catalysis Based On Functional Pincer Ligands. Chem. Rev. 2019, 119 (4), 2681-2751; (b) Trincado, M.; Bösken, J.; Grützmacher, H., Homogeneously catalyzed acceptorless dehydrogenation of alcohols: A progress report. Coord. Chem. Rev. 2021, 443, 213967; (c) Ai, W.; Zhong, R.; Liu, X.; Liu, Q., Hydride Transfer Reactions Catalyzed by Cobalt Complexes. Chem. Rev. 2019, 119 (4), 2876-2953; (d) Wen, J.; Wang, F.; Zhang, X., Asymmetric hydrogenation catalyzed by first-row transition metal complexes. Chem. Soc. Rev. 2021, 50 (5), 3211-3237; (e) Zhang, L.; Zhou, M.; Wang, A.; Zhang, T., Selective Hydrogenation over Supported Metal Catalysts: From Nanoparticles to Single Atoms. Chem. Rev. 2020, 120 (2), 683-733.

7. Perkowski, A. J.; You, W.; Nicewicz, D. A., Visible Light Photoinitiated Metal-Free Living Cationic Polymerization of 4-Methoxystyrene. J. Am. Chem. Soc. 2015, 137 (24), 7580-3.

8. (a) Imamura, K.; Okubo, Y.; Ito, T.; Tanaka, A.; Hashimoto, K.; Kominami, H., Photocatalytic hydrogenation of alkenes to alkanes in alcoholic suspensions of palladium-loaded titanium(iv) oxide without the use of hydrogen gas. RSC Adv. 2014, 4 (38), 19883-19886; (b) Li, J.; Yang, J.; Wen, F.; Li, C., A visible-light-driven transfer 
hydrogenation on CdS nanoparticles combined with iridium complexes. Chem. Comm. 2011, 47 (25), 7080-2; (c) Yamataka, H.; Seto, N.; Ichihara, J.; Hanafusa, T.; Teratani, S., Reduction of C-C multiple bonds using an illuminated semiconductor catalyst. J. Chem. Soc., Chem. Commun. 1985, (12), 788-789.

9. Shimakoshi, H.; Hisaeda, Y., B12-TiO2Hybrid Catalyst for Light-Driven Hydrogen Production and Hydrogenation of C-C Multiple Bonds. ChemPlusChem 2014, 79 (9), 1250-1253.

10. Shiragami, T.; Pac, C.; Yanagida, S., Visble-Light- Induced TwoElectron-Transfer Photoreductions on CdS: Effects of Morphology. J. Phys. Chem. 1990, 94, 504-506.

11. Litman, Z. C.; Wang, Y.; Zhao, H.; Hartwig, J. F., Cooperative asymmetric reactions combining photocatalysis and enzymatic catalysis. Nature 2018, 560 (7718), 355-359.

12. Larionova, N. A.; Ondozabal, J. M.; Cambeiro, X. C., Reduction of Electron-Deficient Alkenes Enabled by a Photoinduced Hydrogen Atom Transfer. Adv. Synth. Catal. 2021, 363 (2), 558-564.

13. Kamei, Y.; Seino, Y.; Yamaguchi, Y.; Yoshino, T.; Maeda, S.; Kojima, M.; Matsunaga, S., Silane- and peroxide-free hydrogen atom transfer hydrogenation using ascorbic acid and cobalt-photoredox dual catalysis. Nat. Comm. 2021, 12 (1), 966.

14. (a) Metternich, J. B.; Gilmour, R., A Bio-Inspired, Catalytic E --> Z Isomerization of Activated Olefins. J. Am. Chem. Soc. 2015, 137 (35), 11254-7; (b) Saltiel, J.; Hammond, G. S., Mechanisms of Photochemical Reactions in Solution. XVII. cis-trans Isomerization of the Stilbenes by Excitation Transfer from Low Energy Sensitizers. J. Am. Chem. Soc. 1963, 85 (16), 2515-2516; (c) Hammond, G. S.; Saltiel, J., Photosensitized Cis-Trans Isomerization of the Stilbenes. J. Am. Chem. Soc. 1962, 84 (24), 4983-4984.

15. Schreier, M. R.; Pfund, B.; Guo, X.; Wenger, O. S., Photo-triggered hydrogen atom transfer from an iridium hydride complex to unactivated olefins. Chem. Sci. 2020, 11 (32), 8582-8594.

16. Czyz, M. L.; Taylor, M. S.; Horngren, T. H.; Polyzos, A., Reductive Activation and Hydrofunctionalization of Olefins by Multiphoton Tandem Photoredox Catalysis. ACS Cat. 2021, 5472-5480.

17. Luo, S. P.; Mejia, E.; Friedrich, A.; Pazidis, A.; Junge, H.; Surkus, A. E.; Jackstell, R.; Denurra, S.; Gladiali, S.; Lochbrunner, S.; Beller, M., Photocatalytic water reduction with copper-based photosensitizers: a noble-metal-free system. Angew. Chem. Int. Ed. 2013, 52, 419-23.

18. Call, A.; Codolà, Z.; Acuña-Parés, F.; Lloret-Fillol, J., Photo- and electrocatalytic $\mathrm{H} 2$ production by new first-row transition-metal complexes based on an aminopyridine pentadentate ligand. Chem. Eur. J. 2014, 20 (20), 6171-83.

19. Lloret-Fillol, J.; Casadevall, C.; León, J.; Call, A.; Casitas, A.; Pla, J. J.; Hernández, P. J.; Caldentey, X. F. Photoreactor. 2017, PCT/EP2018/064177.

20. Call, A.; Franco, F.; Kandoth, N.; Fernández, S.; González-Béjar, M.; Pérez-Prieto, J.; Luis, J. M.; Lloret-Fillol, J., Understanding light-driven $\mathrm{H} 2$ evolution through the electronic tuning of aminopyridine cobalt complexes. Chem. Sci. 2018, 9 (9), 2609-2619.

21. Lloret-Fillol, J.; Codolà, Z.; Garcia-Bosch, I.; Gómez, L.; Pla, J. J.; Costas, M., Efficient water oxidation catalysts based on readily available iron coordination complexes. Nat. Chem. 2011, 3, 807-813.

22. Ghosh, I.; Ghosh, T.; Bardagi, J. I.; König, B., Reduction of aryl halides by consecutive visible light-induced electron transfer processes. Science 2014, 346 (6210), 725-728.

23. The bond dissociation energy (BDE) is lower for aryl bromides than for other aryl halides (DFT calculated bond dissociation energies are as follows: $B D E_{C-B r}=81.9 \mathrm{kcal} \cdot \mathrm{mol}-1$ for substrate 22; $B D E_{C-C l}=93.8$ $\mathrm{kcal} \cdot \mathrm{mol}-1$ for 23, and $B D E_{C-F}=126.0 \mathrm{kcal} \cdot \mathrm{mol}^{-1}$ for 25).

24. (a) Wiedner, E. S.; Chambers, M. B.; Pitman, C. L.; Bullock, R. M.; Miller, A. J.; Appel, A. M., Thermodynamic Hydricity of Transition Metal Hydrides. Chem Rev 2016, 116 (15), 8655-92; (b) Hu, Y.; Shaw, A. P.; Estes, D. P.; Norton, J. R., Transition-Metal Hydride Radical Cations. Chem Rev 2016, 116 (15), 8427-62; (c) Crossley, S. W.; Obradors, C.; Martinez, R. M.; Shenvi, R. A., Mn-, Fe-, and CoCatalyzed Radical Hydrofunctionalizations of Olefins. Chem Rev 2016, 116 (15), 8912-9000.

25. (a) Lo, J. C.; Gui, J.; Yabe, Y.; Pan, C. M.; Baran, P. S., Functionalized olefin cross-coupling to construct carbon-carbon bonds. Nature 2014, 516 (7531), 343-8; (b) Lo, J. C.; Yabe, Y.; Baran, P. S., A practical and catalytic reductive olefin coupling. J. Am. Chem. Soc. 2014, 136 (4), 1304-7
26. (a) Li, G.; Han, A.; Pulling, M. E.; Estes, D. P.; Norton, J. R., Evidence for formation of a Co-H bond from $(\mathrm{H} 2 \mathrm{O}) 2 \mathrm{Co}(\mathrm{dmgBF} 2) 2$ under $\mathrm{H} 2$ : application to radical cyclizations. J. Am. Chem. Soc. 2012, 134 (36), 14662-5; (b) Eisenberg, D. C.; Norton, J. R., Hydrogen-Atom Transfer Reactions of Transition-Metal Hydrides. Isr. J. Chem. 1991, 31, 55.

27. Sang, S.; Unruh, T.; Demeshko, S.; Domenianni, L. I.; van Leest, N. P.; Marquetand, P.; Schneck, F.; Würtele, C.; de Zwart, F. J.; de Bruin, B.; González, L.; Vöhringer, P.; Schneider, S., Photo-Initiated CobaltCatalyzed Radical Olefin Hydrogenation. Chem. Eur. J. 2021, doi: 10.1002/chem.202101705.

28. Litwinienko, G.; Ingold, K. U., Solvent Effects on the Rates and Mechanisms of Reaction of Phenols with Free Radicals. Acc. Chem. Res. 2007, 40 (3), 222-230.

29. Seo, H.; Katcher, M. H.; Jamison, T. F., Photoredox activation of carbon dioxide for amino acid synthesis in continuous flow. Nat. Chem. 2017, 9 (5), 453-456.

30. Wang, J.-W.; Yamauchi, K.; Huang, H.-H.; Sun, J.-K.; Luo, Z.-M.; Zhong, D.-C.; Lu, T.-B.; Sakai, K., A Molecular Cobalt Hydrogen Evolution Catalyst Showing High Activity and Outstanding Tolerance to $\mathrm{CO}$ and $\mathrm{O}_{2}$. Angew. Chem. Int. Ed. 2019, 58 (32), 10923-10927.

31. (a) Friedfeld, M. R.; Zhong, H.; Ruck, R. T.; Shevlin, M.; Chirik, P. J., Cobalt-catalyzed asymmetric hydrogenation of enamides enabled by single-electron reduction. Science 2018, 360 (6391), 888-893; (b) Friedfeld, M. R.; Shevlin, M.; Hoyt, J. M.; Krska, S. W.; Tudge, M. T.; Chirik, P. J., Cobalt Precursors for High-Throughput Discovery of Base Metal Asymmetric Alkene Hydrogenation Catalysts. Science 2013, 342 (6162), 1076-1080; (c) Liu, W.; Sahoo, B.; Junge, K.; Beller, M., Cobalt Complexes as an Emerging Class of Catalysts for Homogeneous Hydrogenations. Acc. Chem. Res. 2018, 51 (8), 18581869.

32. Stevenson, J. P.; Jackson, W. F.; Tanko, J. M., CyclopropylcarbinylType Ring Openings. Reconciling the Chemistry of Neutral Radicals and Radical Anions. J. Am. Chem. Soc. 2002, 124, 4271-4281.

33. (a) Hollis, R.; Hughes, L.; Bowry, V. W.; Ingold, K. U., Calibration of a fast benzylic radical clock reaction. J. Org. Chem. 1992, 57 (15), 42844287; (b) Masnovi, J.; Samsel, E. G.; Bullock, R. M., Cyclopropylbenzyl radical clocks. J. Chem. Soc., Chem. Commun. 1989, (15), 1044-1045.

34. (a) Mejía, E.; Luo, S.-P.; Karnahl, M.; Friedrich, A.; Tschierlei, S.; Surkus, A.-E.; Junge, H.; Gladiali, S.; Lochbrunner, S.; Beller, M., A Noble-Metal-Free System for Photocatalytic Hydrogen Production from Water. Chem. Eur. J. 2013, 19 (47), 15972-15978; (b) Fischer, S.; Hollmann, D.; Tschierlei, S.; Karnahl, M.; Rockstroh, N.; Barsch, E.; Schwarzbach, P.; Luo, S.-P.; Junge, H.; Beller, M.; Lochbrunner, S.; Ludwig, R.; Brückner, A., Death and Rebirth: Photocatalytic Hydrogen Production by a Self-Organizing Copper-Iron System. ACS Cat. 2014, 4 (6), 1845-1849.

35. Fernández, S.; Franco, F.; Casadevall, C.; Martin-Diaconescu, V.; Luis, J. M.; Lloret-Fillol, J., A Unified Electro- and Photocatalytic $\mathrm{CO}_{2}$ to CO Reduction Mechanism with Aminopyridine Cobalt Complexes. J. Am. Chem. Soc. 2020, 142 (1), 120-133. 